\title{
Anhang 6: Historische Verzeichnisse ${ }^{1}$
}

\section{Verzeichnis des wissenschaftlichen Nachlasses von Prof Franz Brentano, soweit er bei seinem Tode in seiner Wohnung vorhanden war.}

1) 31. I. 1916 Von der Unsterblichkeit der menschlichen Seele. (Übersicht) $2 \mathrm{~S}$.

2) 31. I. 1916 Von der Unsterblichkeit der menschlichen Seele. 16 S.

3) 1913-15 (?) Zum Beweis der Geistigkeit der Seele. 6 S.

4) 24. VI. 1915 Gedankengang beim Beweis für das Dasein Gottes. $27 \mathrm{~S}$.

5) 23. VII. 1915 Über Pascals Gedanken zur Apologie der kirchlichen Lehre. $50 \mathrm{~S}$.

6) Über die Lehre Jesu und ihre bleibende Bedeutung. Vorwort. $4 \mathrm{~S}$.

7) 24. VIII. 1915 Die Sittenlehre Jesu nach den Evangelien. 9 S.

8) 2. IX. 1915 Die Lehre Jesu von Gott und Welt und von seiner eigenen Person und Sendung nach den Evangelien (mit einer Abschrift). $15 \mathrm{~S}$.

9) 14. II. 1916 Nietzsche als Nachahmer Jesu. $3 \mathrm{~S}$.

10) 21. XI. 1914 Von dem Unterschied zwischen primärem und sekundärem Kontinuum. 3 S.

11) Vom Kontinuierlichen. $1 \mathrm{~S}$.

12) Vom Kontinuierlichen. $6 \mathrm{~S}$.

13) 22. XI. 1914 Vom Kontinuierlichen. $51 \mathrm{~S}$.

14) 16. XII. 1915 Nachtrag zur Abhandlung über das Kontinuierliche. $5 \mathrm{~S}$.

15) 2. III. 1916 (Über die Kategorien.) $27 \mathrm{~S}$.

16) 29. III. 1916 Fortsetzung über die Kategorien. $40 \mathrm{~S}$.

17) 13. I. 1916 Zur Axiomatik. 3 S.

18) 8. V. 1916 (Über Teil und Ganzes.) 5 S.

19) 16. XI. 1915 Metaphysik. $33 \mathrm{~S}$.

20) 16. XII. 1915 Zur Metaphysik. 42 S.

21) 23.V. 1916 Zur Einführung in die Metaphysik (Einteilung). 4 S.

22) 23.V. 1916 Zur Einführung in die Metaphysik. $28 \mathrm{~S}$.

23) 15. VI. 1916 (Metaphysik, Inhaltsübersicht.) 2S.

24) 16. VI. 1916 (Metaphysik, Inhaltsübersicht.) $3 \mathrm{~S}$.

25) 6. VII. 1915 (Disposition für den Beweis für das Dasein Gottes.) $2 \mathrm{~S}$.

26)

27) Zu Erich Bechers „Weltgebäude“. 15 S. Lehre von den Universalien. $10 \mathrm{~S}$.

$1 \mathrm{Zu}$ den Quellenangaben für die einzelnen Verzeichnisse vgl. Anhang 4, $348 \mathrm{f}$. 
28)

29) 5. I. 1916

30) 12. I. 1915

31) 20. I. 1916

32) 20. I. 1916

33) 28. I. 1916

34) 26. I. 1916

35) 11. II. 1916

36) 16. II. 1916

37) 20. IV. 1916

38) 20. V. 1916

39) 2. VI. 1916

40) 23. I. 1916

41) 12. V. 1916

42) 3. V. 1916

43) 23. V. 1916

44) 6. III. 1916

45) 15. V. 1916

46) 28. VI. 1916

47)

48) 11. VI. 1916

49)

50) 23. X. 1916

51) 24. X. 1916

52) 5. XI. 1916

53) 6. XI. 1916

54) 17. XI. 1916

55) 22. XI. 1916

56) 1. XII. 1916
Zur Lehre von der Zeit. 5 S.

Aphorismen über die Musik. 5 S.

Von den Universalien. 20 S.

Von der Gleichheit und Verschiedenheit und deren Erkenntnis. $2 \mathrm{~S}$.

Über Gleichheit, Ähnlichkeit, Identität, Analogie. 2 S.

Gegen die Annahme als besondere Grundklasse psychischer Beziehungen. $2 \mathrm{~S}$.

Von der Teilnahme alles Räumlichen an dem allgemeinen Charakter alles Zeitlichen. 3 S.

Zur Lehre von Anschauung und Allgemeinbegriff. 5 S.

Evidenz des Kontradiktionsgesetzes. 23 S.

(Kant über Intensität.) $3 \mathrm{~S}$.

Von der Trägheitstendenz. $1 \mathrm{~S}$.

Zur Universalienlehre. $1 \mathrm{~S}$.

Von den sogenannten Objektiven. $2 \mathrm{~S}$.

Die Weisheit, ihr wissenschaftlicher Charakter, ihre Aufgabe im einzelnen. $4 \mathrm{~S}$.

Boltzmann „Populäre Schriften“. Über die Frage nach der objektiven Existenz der Vorgänge in der unbelebten Natur. 3 S.

Über die schöne Unterscheidung von Existenz und Sein. 4 S.

Von der Bestimmung qualitativer Abstände. $3 \mathrm{~S}$.

Über die Kompatibilität gewisser blinder und konfuser Urteile mit entgegengesetzten evidenten. $2 \mathrm{~S}$.

Zur Lehre von der Zeit. 2 S.

Zeit. 5 S.

Von der Wahrscheinlichkeit. $24 \mathrm{~S}$.

Wahrscheinlichkeit - Exzerpt. 4 S.

$\mathrm{Zu}$ Poincarés Bemerkungen über die Wahrscheinlichkeit in „Wissenschaft und Hypothese“. 5 S.

Zum Bertrandschen Problem der Wahrscheinlichkeit, dass eine nicht näher bestimmte Sehne eines Kreises größer oder kleiner sei als die Seite des eingeschriebenen regelmäßigen Dreiecks. $9 \mathrm{~S}$.

Zu Bertrand, calcul des probabilités. $6 \mathrm{~S}$.

$\mathrm{Zu}$ Bertrand, calcul des probabilités. $1 \mathrm{~S}$.

Poincaré - Von der Wahrscheinlichkeit. $7 \mathrm{~S}$.

Poincaré - Über den Zufall. 6 S.

$\mathrm{Zu}$ Poincarés Erkenntnislehre. $25 \mathrm{~S}$. 
57) 16. XII. 1916 Von Poincaré behandelte erkenntnistheoretische Fragen. 3 S.

58) 19. XII. 1916 Zu Poincarés erkenntnistheoretischen Aufstellungen. 17 S.

59)

60)

61) 7. IV. 1914

62)

63) 17. IV. 1916

64)

65) 17. VI. 1916

66) VII. 1916

67) VIII. 1916 Kant. Ontologischer, kosmologischer und teleologischer Beweis. $10 \mathrm{~S}$.

Hume - Gespräche über die natürliche Religion. $3 \mathrm{~S}$.

Bemerkungen zu Hume's Gesprächen über die natürliche Religion. $6 \mathrm{~S}$.

Clarke - Über das Dasein und die Attribute Gottes. $10 \mathrm{~S}$.

Korrespondenz von Leibniz' und Clarke. $6 \mathrm{~S}$.

Kritisches zu Leibniz Optimismus. 6 S.

Thomas Reid. 5 S.

$\mathrm{Zu}$ Reid. $11 \mathrm{~S}$.

Über Royer-Collards von Jouffroy mit der Übersetzung von Reid veröffentlichte Fragmente. 4 S.

68) 14. VIII. 1916 Reid. 23 S.

69) 5. IX. 1916 Was an Reid zu loben und zu tadeln. $21 \mathrm{~S}$.

70) 1. I. 1917

Gedankengang beim Beweis für das Dasein Gottes. $1 \mathrm{~S}$.

71) 2. I. 1917

Gedankengang beim Beweis für das Dasein Gottes. $2 \mathrm{~S}$.

72) 5. I. 1917

Gedankengang beim Beweis für das Dasein Gottes. 2 S.

73) 10. I. 1917

Über das Prinzip des zureichenden Grundes. $10 \mathrm{~S}$.

74) 27. I. 1917

Zur Lehre von den entia rationis. $8 \mathrm{~S}$.

75) 7. I. 1917

Zum Bertrandschen Wahrscheinlichkeitsproblem. 4 S.

76) 10. I. 1917

Zum Bertrandschen Problem. 8 S.

77)

Diese Nummer aus Irrtum ausgeblieben, es entspricht ihr kein $M$ M. $^{2}$

78) 22. I. 1917 Zum Bertrandschen Problem. 4 S.

79) 24. I. 1917 Zum Bertrandschen Sehnenproblem. 4 S.

80) 5. II. 1917 (Ein gedachter Taler ...) $8 \mathrm{~S}$.

81) 6. II. 1917 Vom ens rationis. $28 \mathrm{~S}$.

82) 17. II. 1917 Aphorismen. 1 S.

83) 21. II. 1917 Universell Denkendes und individuell Seiendes. 4 S.

84) 21. II. 1917 Universell Denkendes und individuell Seiendes. 1 S.

85) 23. II. 1917 Zur Lehre von Raum und Zeit. $28+4$ S.

86) 9. III. 1917 Anschauung und abstrakte Vorstellung. 7 S.

87) 1906, Herbst Von der Zeit (Ms von Brentanos Hand)

88) Zeitursprung (Ms von Brentanos Hand)

89) 2. V. 1908 Von der Zeit.

90) Zur Lehre von der Zeit. 5 S.

2 Handschriftliche Anmerkung von Emilie Brentano. 
91) 2. XI. 1914 Von der Zeit. $21 \mathrm{~S}$.

92) 10. XI. 1914 Von der Zeit. 21 S.

93) 15. XI. 1914 Zur Zeit. 10 S.

94) 17. XI. 1914 Der Vorwurf des Psychologismus. 1 S.

95) 4. I. 1915 Von der Zeit. $9 \mathrm{~S}$.

96) 18. I. 1915 Ob die Temporalmodi zu den modis obliquis zu rechnen. $8 \mathrm{~S}$.

97) 24. I. 1915 Gegen Martys Zeitlehre. 17 S.

98) 26. I. 1915 Leibniz - Russell. 4 S.

99) 30. I. 1915 Zur Lorenz-Einstein-Frage. 8 S.

100) 1. II. 1915 Zur Lehre von der tatsächlichen unmittelbaren Evidenz. $1 \mathrm{~S}$.

101) 4. II. 1915 Zur Lehre von der Zeit. $11 \mathrm{~S}$.

102) 6. II. 1915 Zur Zeit. 5 S.

103) 7. II. 1915 Zur Zeitlehre. 4 S.

104) 7. II. 1915 Zur Lehre vom Raum. $10 \mathrm{~S}$.

105) 9. II. 1915 Zur Lehre von der Zeit. $10 \mathrm{~S}$.

106) 9. II. 1915 Über unmittelbare Zeitfolge, zeitliche Berührung und unmittelbaren zeitlichen Zusammenhang. 5 S.

107) 13. II. 1915 Zur Zeitlehre. 17 S.

108) 14. II. 1915 Raum und Zeit. 2 S.

109) 28. II. 1915 Die Zeit. 2 S.

110) 1. III. 1915 Die Zeit. 3 S.

111)

Von Differenzen, welche unterindividuell sind. $1 \mathrm{~S}$.

112) 3. III. 1915 Was versteht man gemeiniglich unter Zeit? $3 \mathrm{~S}$.

113) 4. III. 1915 Ausgangspunkte für die Untersuchung über die Zeit. 3 S.

114) 8. III. 1915 Schwierigkeiten der Zeitfragen. 1 S.

115) 10. III. 1915 Zu Lorenz' Erklärungsversuch der von Michelson gemachten Erfahrungen. 4 S.

116) 12. III. 1915 Aristoteles über die Zeit. 9 S.

117) 11. III. 1915 Aristoteles Physik. 2 S.

118) 17. III. 1915 Kant über die Zeit. $14 \mathrm{~S}$.

119) 22. III. 1915 Von der Zeit. $14 \mathrm{~S}$.

120) 27. III. 1915 Zu Leibniz' Lehre von Raum und Zeit. 6 S.

121) 2. IV. 1915 Aristoteles - Von der Zeit. 3 S.

122) 29. IV. 1915 Früher oder später. $7 \mathrm{~S}$.

123) 30. IV. 1915 (Von der Zeit). $5 \mathrm{~S}$. 


\section{Provisorisches Verzeichnis sämtlicher Manuskripte, Kopien, Briefe, Notizen etc betreffend die Hinterlassenschaft von Franz Brentano, soweit sie sich in Verwahrung von Prof. Oskar Kraus befindet. Nach dem Stand im April 1917. Die Zeit der Abfassung der einzelnen Abhandlungen wird später noch festzustellen sein. ${ }^{3}$}

No. 1. Von den Objekten. 7 Blätter Maschinenschrift. Etwa 1910/11.

2. Vom Denken und vom ens rationis. Diktat. 13 Blätter doppelseitig geschrieben. „Erhalten am 18. März 06“ (mit eigenhändigem Zusatz). Dazu weitere 4 Blätter Anhang.

3. Über den Begriff des Realen. 2 Blätter (Viertelbogen). Stenogramm von Kraus, Fragment. Aufzeichnungen aus Florenz 1908.

4. $\quad$ Psychische Tätigkeiten. 6 Viertelbogen. Krausstenogramm 08.

5. Begriff des cogitare. Diktat. Krausmskpt. 2 Bl. Viertelbog. Ex 1904??

6. Gegenstand Wirklichkeit Seiendes Relation (ohne Titel) Brentanohandschrift. 11 Halbbogen doppelseitig beschr. Jahr wohl vor der Operation?

7. Die psychischen Betätigungen. Fragment. Eigenschrift, 1 Bogen.

8.a Der Name existierend und seine Äquivokationen. 6 Bogen, davon 3 Eigenschrift und drei Bleistiftschrift von Kraus.

8.b Dasselbe von Kraus geschr. 9 Viertelbogen. ex 07 oder 08?

9. Vom analytischen Urteil. 9 Martyblätter (Viertelbogen) ex 07 oder 08.

10. Anmerkungen zu Mach Erkenntnis und Irrtum. Brentanodiktat. Zu Capitel 11 = 14 Halbbogen, zu Capitel XII = 7 Halbbogen eine Martycopie hievon besitz Kastil.

11. Selbstbewusstsein, Ich, Substanz. Machinoskript. Kopie besitzt auch Kastil.

11. Maschinenbogen vorl. Formats.

12. Continuität. Martyskript. „aus verschiedenen Jahren“ ex ? Älteren Datums. 6 Viertelbogen.

13. Eine Abhandlung über das Continuum und verwandte Fragen, Martyskript in Viertelbogen 1-10a und 10b bis 73. Dabei Beweis, dass die Punktmenge einer Geraden gleichmächtig der Punktmenge eines Quadrats. Abcd und alpha beta. Jahr? Älteren Datums.

14. Über das Kontinuierliche mit drei Nachträgen wovon einer nach mündlichen Bemerkungen von Kastil niedergeschrieben ist.

1. Abhandlung 24 Seiten Kanzleiformat. Machinoskript.

2. Erster Nachtrag. 8 Seiten Kanzleiformat. Machinoskript.

3 Kursiver Text bezeichnet handschriftliche Ergänzungen; die Handschrift ist die von Oskar Kraus. 
3. Zweiter Nachtrag. 8 Seiten Kanzleiformat.

4. Dritter Nachtrag. 2 Seiten.

Die Abschrift ist gekürzt, Original in Zürich.

Kopien besitzen Kraus, Kastil, Eisenmeier, Baronin Reicher?

15. Von der Zahl und dem analytischen Charakter der algebraischen Wahrheiten. Martyskript.

5 Viertelbogen (eine Abschrift besitzt Eisenmeier sub. Zahl XVII) und 1 Duplikat. Machinoskr.

1 Kanzleibogen. Und wohl auch andere besitzen die Maschinenkopie.

16. Über den Ursprung der mathematischen Erkenntnis. Martyskript. 19 Viertelbogen. Ex 1900. (dasselbe noch einmal in schlechtem Krausstenogramm in grauem Heft enthält auch den Nachw. zum 11. Euk. Axiom. (= No XI Eisenmeierinventar)

17. Das Parallelenaxiom. Martyskript. 6 Viertelbogen. (= XII des Eisenmeierinventars)

18. Beweis, dass die gerade Linie die kürzeste zwischen zwei Punkten. Martyskript. 6 Viertelbogen.

19. Von dem empirischen Element in unserer Algebra und der Frage, ob und inwiefern dasselbe ihre Allgemeingiltigkeit beschränkt. 1 Martyskript 3 Bogen und zwei Duplikate Machinoskr. 1 Kanzleibogen. (= XVIII Eisenmeierinventar)

20. Kopie eines Briefes an Kraus über Cantor und den Begriff der wohlgeordneten Menge etc. Machinoskr. Mangelhaft, Jahr festzustellen. (gleiche Kopie bei den Briefabschriften.) 1 Kanzleibogen.

21. Copie eines Briefes an Kraus über mathematische Fiktionen. (gleiche Kopie bei den Briefabschriften.) Jahr festzustellen, 1 Kanzleibogen.

22. Gegen die Behauptung der Willkür der ersten Annahmen bei der Bestimmung einer Wahrscheinlichkeit (Bertrandsches Problem). 1 Kanzleibogen. NB Eisenmeier besitzt sub XXVIII Briefe an Kraus über Größe Kontinuum etc., wahrscheinlich = den sub 20, 21 genannten (No 22 doppelt).

23. Vom Unendlichen. Eine Inhaltsangabe. 5 Viertelbogen. Skriptum von Eisenmeier (dasselbe Krausskriptum nach Eisenmeier in Heft No 24).

24. Wachsleinwandheft. Enthaltend Notizen nach mündlichen Mitteilungen, zumeist Überlegungen zum Unendlichkeitsproblem, Jahr 1902, Schönbühel. Mit Bleistift, leserlich. Jemand besitzt eine gepauste Kopie (hiezu angeblich 2 Briefe von Kraus). Dieses Heft enthält Abschrift von No 23. Auf der letzten Seite Notizen aus früheren Jahren über die Termini Holokterie Merklorie [?] = der späteren Plerose und Teleiose. 
25. Ein Beweis für das 11. Euklidsche Axiom. Krausskriptum. 6 Blättchen.

26. Ursprung der Raumvorstellung. Martyskript bis Seite ad 36, mit vielen eingeschobenen Blättern, die nicht gezählt sind. Alles paginiert, Viertelbogen (älter).

27. Vom Raume. Martyskript. 7 resp. 8 Blätter Viertelbogen (neueren Datums. Wohl gegen M.).

28. Vom Raume. Machinoskript. 2 Bogen Kanzleiformat. In duplo.

29. Briefcopie. Machinoskript nach einem Briefe an Marty ex 1912. Erster Angriff auf Martys Raumlehre.

30. Woher unsere Raumvorstellung. Martyskript. Jahr? 11 Viertelbogen (p. 5, 6 fehlt).

31. Was ist unter Raum zu verstehen? Martyskript. 2 Viertelbogen. 2 Entwürfe zu 5 und VI, Viertelbogen (p. 4 fehlt).

32. Von der Größe. Machinoskript (= XXV Eisenmeierregister). 51 Viertelbogen. Ex 1904 oder früher.

33. Über den Begriff der Wahrheit. Hektographiertes Heft. 33 doppelseitig beschriebene halbe Kanzleibögen. Mit Umschlag. Rechts oben No 24, woraus ersichtlich, dass mindestens so viele Exemplare. Unten: $1889 \mathrm{zu}$ Zwecken der Discussion in der philosophischen Gesellschaft an der Universität Wien als Manuskript vervielfältigt.

34.a-c Zu Theophrast. Brentanodiktate. Kraus zum Zwecke des Studiums übergeben. Drei Hefte. Halbbrüchig [?] beschriebene Kanzleibögen.

35. Der ungedruckte Teil der Abhandlung Krasnopolskis letzter Versuch von Seite 23-37 (16 Halbbögen Kanzleiformat).

36. Zur Lehre von Raum und Zeit vom 23. II. 1917 (11 Blätter, Seite 8 fehlt. Unvollständig, wird in Innsbruck kopiert).

37. Drei kleine Abhandlungen über die Zeit: I. Zur Lehre von der Zeit (,Was ist unter Zeit zu verstehen?“) II. „Wie kann etwas ...“ III. Zur Lehre von der Zeit (28.VI. 1916, Fragment), nach stenographischen Abschriften Kastils in Innsbruck kopiert. Kanzleiformat, 13, 5 und 3 Seiten (S. 1-7, S. 8-13 und 3). Originale in Zürich; teilweise auch von Kraus stenographisch notiert, in Notizbüchern aus Zürich (unten 217).

38. Zur Geschichte des Zeitproblems bei Brentano und mir. Notizen von Marty aus verschiedenen Jahren, so z. B. 1894, 1898, 1902 und 1910, und anderen noch nicht festgestellten Jahren.

39. Aus einem alten Psychologiekolleg Martys, der Brentanos Lehren vortrug.

40. Ein Brief Martys an Brentano mit seinen Antworten und einem antwortenden Brief vom März 1895. 
41. Skizze einer Lehre von der Zeit. Zweifellos eine Abschrift Martys (geht insbesondere aus einer Bemerkung Martys S. 15 hervor, ist aber ohnedies zweifellos ein Entwurf Brentanos. 15 Quartseiten, dann 3 S. = A, B, C, und weitere vier Seiten „Zur Zeitskizze“). Jahr? Mitunter Schlagwortartig. Die Zeit als Modus des Urteils gefasst.

42. Von der Zeit. Aus dem Jahre 1899, Florenz. 40 Quartseiten. Machinoskript. Auch im Besitze anderer, z. B. Kastils.

43. Vier sehr alte Blätter über Zeit, wohl nach einem alten Kolleg Brentanos. Zweifelhaft.

44.a Brentano über Urbachs Zeitlehre. Abschrift Martys. 12 Quartseiten. Eisenmeier besitzt Abschriften der Briefe Brentanos an Urbach!

44.b Gegenüberstellung der Zeitlehre Martys und Brentanos. 13 Briefseiten. Gehört zu dem Briefwechsel Brentano-Kraus.

45. Gegen Martys Zeitlehre. 11 Viertelbogen aus Brentanobrief entnommen. 43 + 44 stammen aus dem Jahre 1914 nach dem Tode Martys. Gehört zu Krausbriefen.

46. Universalien. 13 Bogen. Kanzleiformat. Nach Kastils Stenogramm.

47. Zur Kategorienlehre. Stenographische Abschrift genommen in Schönbühel 1913. 7 Kanzleibogen. Krausskriptum.

48. Kategorienlehre. Abschrift von Kraus. 7 Seiten Oktavformat.

49. Vom Seienden. Martyabschrift. Viertelbogen I-IV.

50. Vom Seienden. Martyabschrift. 1 Viertelbogen + Notiz vom 31. VII. 1902.

51. Substanz und Accidenz. Martyabschrift. Halbbogen A-D.

52. Vom ens rationis. Martyabschrift. 3 Seiten. (49-51 älter, 52 erklärt die mentale Inexistenz für fiktiv. Nach Kraus Meinung nach 1903, vide Krausnotizen ex Hinterbrühl.)

53. Historisches zu res und ens rationis. Vier Viertelbogen. Alt.

54. Aristoteles Lehre vom Seienden. 2 Viertelbogen neueren Datums. Kritisch.

55. Das Seiende. Martyskript. Anerkennt noch nichtreale Bestimmungen. Vier Seiten Viertelbogen.

56. Vom intentional in sich haben. Martyskript. 4 Viertelbogen.

57. Entwurf einer Psychognosie. 4. Sept. 1901 begonnen, am 7. Sept 1901 beendet. Abschrift von Kraus in kleinem Wachsleinwandheft 59 Seiten.

58. Dasselbe in Abschrift von Eisenmeier und Marty. S. 1-39, Viertelbogen. Teilw. schön geschrieben.

59. Psychologische Skizze (andere Arbeit als 57, 58). Martyskript. 1-10, Viertelbogen.

60. Andere Bearbeitung der Psychognosie. S. 1-15, Martyskript. 
61. Unterscheidung von psych. Substanz, psych. Tätigem und psychisch sich Beziehendem. Zwei Martyblätter (auch primäres und sekundäres Objekt).

62. Von der Substanz. Ein von Kraus geschriebenes (teilw. stenograph.) Heft in grauem Umschlag (Schulheft) aus Schönbühel, Jahr 1900. Teilw. bereits durch die psychognostischen Skizzen überholt. Enthält auch die Abschrift eines Briefes an Amato über dessen Monadologie, der auch von Eisenmeier (= No XIV) kopiert ist und so auch sub No. 63.

63. Brief an Amato über dessen Monadenlehre. Martyskript. 21 Viertelbogen.

64. Von der Substanz. Zwei kleine Abhandlungen $(\mathrm{A}+\mathrm{B}) \mathrm{zu} 2$ Viertelbogen mit einer Reihe von Notizen nach Brentano aus den Jahren 1902-10 von Martys Hand. (A interessant, rührt bereits an die Lehre, dass Relatives $u$. unbestangeschaut [sic!] wird.)

65. Zwei Abhandlungen über Substanz und Continuum, von Martys Hand aus Schönbühel 1913 27. Juli (3 Viertelbogen = A, B, D (C fehlt?) und 5 Viertelbogen!!). Wichtig zur Continuitätslehre.

66. Einfache und zusammengesetzte Urteile. 3 Martyblätter.

67. Sichvorstellen, Urteilen, Glauben, Annehmen. 4 Martyblätter.

68. „Es gibt nichts als Seiendes“. 2 Martyblätter mit Notizen aus Schönbühel. Nach Brentano. Jahr?

69. Moderne Irrtümer über die Erkenntnisse der Gesetze des Schließens. Martyskript. 16 Viertelbogen. Gleiche Abschrift besitzt Eisenmeier und ist enthalten in Wachsleinwandheft „Philos. Vorträge und Abhandlungen von Franz Brentano“ (No 99).

70. Vom Nominalismus gegen Guastalla. Martyskript. 29 Viertelbogen.

71. Von der Natur der Vorstellung. Machinoskript. Dasselbe in Krausstenogramm. Ein Diktat an Eisenmeier, August 1903 (Eisenmeierverzeichnis = No XXIII).

72. Von der Erkenntnis. Machinoskript, 45 Viertelbogen (Eisenmeier No XXXIX). Jahr? 1902? Oder noch früher?

73. Gedächtnis und Erinnerung. Unter der Aufschrift „zu Meinong“ von Marty gesammelt und geschrieben. Unvollständig, lückenhaft.

74. Zu Meinongs Relationstheorie. 2 und 8 Blätter. „Der Verfasser vermeidet absichtlich nicht bloß mein Colleg sondern auch meine Druckschriften zu zitieren“. 9 Marty Viertelbogen.

75. Notizen zu Hering. 11 Marty Viertelbogen aus verschiedenen Jahren.

76. Über Bemerken und negatives Wahrnehmen. 4 Marty Viertelbogen.

77. Über den simultanen Contrast. Machinoskript. 3 Seiten Kanzleiformat.

78. Die Grünfrage. Machinoskript. 72 Viertelbogen. (= VIII Eisenmeierskript?) 1900. Abschrift auch im Wachsleinwandheft von Kraus No. 
79. Von der Verschmelzung der Töne (= XXXV Eisenmeierskript).

[Nr. 80 fehlt.]

81. Notwendigkeit einer ersten Ursache. 6 Martybogen (= XXIX Eisenmeier). Dasselbe in Machinoskript 7 Seiten. Dazu 3 Seiten eines Briefes über den Contingenzbeweis an Eisenmeier 3 Viertelbogen. Geschrieben von B. Kraus.

82. Zur anfangslosen Bewegung. 3 Marty-Viertelbogen.

83. (Lag bei 82:) Über mehrdimensionale Welten und unsere Anschauung. p. I-III. Martyskript. Viertelbogen, und 6 weitere Seiten. Jahr?

84. Von dem Nachweis eines unmittelbar notwendigen Wesens und seiner Beziehung zum Gottesbeweis. Martyskript. Unvollständig, nur bis § 10 (8 Seiten). Aus dem Jahre 1912 (dasselbe vide unten von Kraus geschrieben).

85. Von dem Nachweis eines unmittelbar notwendigen Wesens und seiner Beziehung zum Gottesbeweis. Martyskript. Abschrift von Kraus. Wachsleinwandheft. 1912. Linksseitig kommentatorische Notizen.

86. Die Atomistik. Abschrift von Arthur Chitz und Kraus nach einem Krausstenogramm, das beiliegt. 20 Seiten (Viertelbogen).

87. Bemerkungen zu Stallo. Krausstenogramm. 3 [Bogen] Kanzleiformat. (Marty besaß eine Abschrift, die nicht auffindbar ist. Wer hat sie?)

88. Zeitbewegende philosophische Fragen. 1. Positivismus 93/94 (= Eisenmeier XL). 39 paginierte Viertelbogen. Martyskript. Dazu 3 ebensolche Blätter vorn und 2 hinten. Nach S. 214 Blätter I-IV vom 31. Juli zum Jamesvortrag vermutlich von Brentano $\mathrm{zu}$ J. Vortrag am Bologneser Congreß. Vide 99.

89. Monismus. Aus zeitbewegende philosophische Fragen. Martyskript. 18 Viertelbogen (= Eisenmeier XL). Vide 99.

90. 7 Blätter zur Gottesfrage. Martyskript. „Gottheit“.

91. Gedankengang beim Beweise für das Dasein Gottes. 24. Juni 1914. Machinoskript nach Kastil, September 1916. Original Zürich. Stenogramm besitzt auch Kraus.

92. Martyaufzeichnungen ex $1913 \mathrm{zu}$ Notwendigkeit und Zufall. 3 Viertelbogen.

93. Der Fehler im Argument des jungen Benjamin Franklin. Machinoskript, doppelt. 9 Viertelbogen. (Dasselbe in Krausstenogramm mit Bemerkungen zum Kolleggebrauch.)

94. Vom Schlechten und seiner Vereinbarkeit mit der Allgüte Gottes. Machinoskript, 7 Viertelbogen.

95. Über die sittliche Vollkommenheit der ersten Ursache aller nicht durch sich selbst notwendigen Wesen. 10 Viertelbogen, Machinskript. 
96. Von der Seligkeit Gottes und ob die ewige Freude, die er genießt, eine intensive sei. Machinskript, 5 Viertelbogen.

97. Gott und Welt. Abschrift von Kraus nach 1905. 25 Seiten (Briefpapiers). (dazu Bleistiftstenogramm)

98. Briefe an Faggi ex 99 (25. März 1899). Über die Optimismusschrift von Faggi. Zwei Briefabschriften von Martys Hand zu 4 und II Seiten.

99. Wachsleinwandheftchen Krausstenogramme nach Eisenmeier, und zwar enthaltend:

Die Grünfrage (= No 78)

Zeitbewegende philosophische Fragen (= 88)

Moderne Irrtümer über die Erkenntnisse des Schließens (= No 69)

Ferner: Zur Methode der historischen Forschung auf philosophischem Gebiete !! (= Eisenmeier No III)

Zur Methode aristotelischer Studien (= Eisenmeier No IV)

Die Gesetze der Wechselwirkung der Naturkräfte (= Eisenmeier I)

Schellings Philosophie (= Eisenmeier V) ex 1889

darin Schellings Philosophie in ihren verschiedenen Phasen 1866 (Habilitation)

Poesie und Prosa (= Eisenmeier No IX)

100. Von der Unsterblichkeit der menschlichen Seele. Machinskript Zürich. 33 Seiten Kanzleiformat und S. a und b (auch in Krausstenogramm vorhanden).

101. Brief an Utitz über die menschliche Seele. Ein Kanzleibogen, Maschinskript. Schönbühel 14. Okt. 1916.

102. Von der Tierseele. Machinskript. 23 Viertelbogen (,und dem eventuellen psychischen Leben der Materie“).

103. Über das Denken sofern es Ausgedehntem eignet. Martyskript. 6 Viertelbogen.

104. Immaterialität und Unsterblichkeit. Ex 1899. Martyskript. p. I-IV und weitere 4 Blätter.

105. Zur Würdigung der Puntini del corso obbligatorio d'anatomia. Ein Wachsleinwandheft mit 2 Nachträgen zu den Puntini, geschrieben von Kraus (nach Eisenmeiers Kopien = No XXII). Dasselbe in Martyabschrift: 12 Viertelbogen, wobei 11. fehlt.

106. Über die Unsterblichkeit. Martyskript älteren Datums. 17 Viertelbogen.

107. Unsterblichkeit. Martyskript. 30 Viertelbogen +1 Blatt betreffend Ehrenfels.

108. Woher kommt die Seele? Martyskript. 5 Viertelbogen +1 Zettel.

109. Über Unsterblichkeit und Dasein Gottes. Martyskript. p. I-XIII. 
110. Geistigkeit der Seele. Martyaufzeichnungen ex 1913, Schönbühel.

111. Über die Lehre Jesu. Machinskript nach Kastilabschrift 1916.

112. Drei Briefe Brentanos an Dr. Breuer in Wien über Darwinismus, Teleologie und Metaphysik. Krausabschrift aus Hinterbrühl 1903. Wachsleinwandheftchen, stenographiert.

113. Brief an Boltzmann, nebst dem vorangegangenen Briefe von Boltzmann. 6 Viertelbogen Krausabschrift und ein Brief an Mach 13 S. (Viertelbogen) ex 1903 19/11 und 22/11.

114. Brief an Urbach über dessen Leibnizbuch. 1900. Martyskript, 7 Seiten.

115. Aus Briefen an Petronievicz. 6 Martyseiten.

116. Brief über Wagner und dekadente Kunst. Vermutlich an Ehrenfels. 3 Martyseiten.

117. Zwei Briefe an Stumpf, der eine über innere Beobachtung !!! ex 1906, der andere über Verschmelzung, ohne Datum. 3 und 4 Martyseiten.

118. Diverse Abschriften aus Briefen an Eisenmeier. Martyskript.

119. Abschriften aus zahlreichen Briefen an Kraus. Martyskript.

120. Briefe an Bergmann. Abschriften und Originale.

121. Dialog Marty-Brentano mit Mitteilungen an Kraus über den Raum. Martyskripte und Kraus-Machinoskript.

122. Abschriften von Briefen Brentanos über Causalität mit einigen Martybriefen. Machinoskripte aus den Jahren 1911-12 (meist Kanzleiformat).

123. Abschriften von Briefen an Stumpf und Köhler über Tonpsychologie aus dem Jahre 1911. Doppelt. Machinskript.

124. Briefe an und über Gomperz Harry an Kastil. Machinoskript. September 1912.

125. Brentano über die Meinongschule. Ein Brief von Brentano an Unger vom 29. Juli 1903. Mit Martyblättern durchsetzt.

126. Blätter über das System der Wissenschaft aus verschiedenen Jahren. Martyskript (vgl. Kraus Notizen aus Lausanne). Notizen.

127. Zur Ontologie. Martynotizen aus verschiedenen Jahren 1899, 1909, 1910.

128. Martynotizen nach Brentano zur Erkenntnistheorie 1890, 1898, erwähnt einen wissenschaftlich sehr bedeutenden Brief über den Willen an Stumpf!

129. Blätter, Martynotizen nach Brentano über rationale Physik ex 1900, 1910 etc.

130. Martynotizen nach Brentano über Continuum und Zahl aus den verschiedensten Jahren (früherer Fascikel XXXVII).

131. Logik und Erkenntnistheorie. Martynotizen 040611.

132. Vom Guten. Vortrag. Martyskript. 20 beschriebene Seiten. Alt. 
133. Ethische Bewegung. 3 Martyseiten.

134. Über Rechtsphilosophie. 10 Martyseiten +6 .

135. Methode der historischen Forschung auf philosophischem Gebiet. 14 Martyseiten (= No 99 = Eisenmeier No III).

136. Über Paulus. Zwei Martyseiten.

137. Zur Harmonielehre. 6 Martyseiten.

138. Von der Erkenntnis des Guten und Schlechten. 3 Martyseiten.

139. Notizen aus Florenz 1901 nach Eisenmeier. 68 Seiten (Kraus B. u. O. samt Register). (Original bei Eisenmeier.)

140. Brentaniana nach Eisenmeier. Martyskript, 19 S.

141. Ibsen als Moralist. Machinoskript, 17 Viertelbogen +2 Viertelbogen (Poesie und Prosa).

[142 fehlt]

143. Zur Ästhetik. Martyskript.

[144 fehlt]

145. Zur Poetik von Scherer. 9 Martyseiten.

146. Ästhetisches. Scheint von Brentano.

147. Zur Ästhetik. Martyskript zum Vortrag über das Schlechte. 3 S. Über Arsis und Thesis und verschiedenes. Excerpte vielleicht von Marty?

148. Brentaniana: Martyskripte aus Schönbühel etc. Verschiedenstes. Noch zu [?] und $z u$ [?]!

149. Ethik Brentaniana.

150. Ethik Brentaniana. Auch Naturrecht. Martyskript.

151. Über Thomas und anderes. Vieles von Brentano. Von dem Wertverhältnis der Güter, Gesetze, ethische Fragen, Politik, Pflichten. Einiges aus 1910.

152. Über Kant. Von Brentano und einiges von Marty.

153. Entia media, entia rationis. Unter dieser von Marty herrührenden Überschrift Verschiedenes ex 1902 und anderen Jahren.

154. Philosophie im Allgemeinen. Der Philosoph. Diverses. Martynotizen ex 1905, 1909, 1910.

155.a Ein Fascikel Psychologisches betreffend und zwar Sinnespsychologie. Brentaniana aus verschiedenen Jahren 1890, 1900, 1902. Tonpsychologie 1898. Martyskript.

155.b Brentaniana über Vortstellen und Urteilen. Martyskript.

156. Brentaniana: Psychologisches etc. Martyskript.

157. Brentaniana: Psychologisches, Vorstellen und Urteilen etc. Martyskript.

158. Brentaniana: Gegenstandstheorie zu Bolzano, zu Syroff [?] etc. Martyskript.

159. Brentaniana: Gestaltsqualität. Einiges mag auch von Marty sein. 
160. Brentaniana: Sinnespsychologie und Gestaltsqualität. 1899. Martyskript. 161. Brentaniana: Interesse. Martyskript.

162. Apperception und innere Wahrnehmung. Briefabhandlung von Brentano. 7 Martyseiten.

163. Über Abstraktion und Begriffsbildung. Verschiedene Brentaniana aus verschiedenen Jahren. Martyskript.

164. Brentaniana mit der Überschrift Wiedererkennen. Martyskript.

165. Brentaniana ohne Aufschrift.

166. Brentaniana mit Aufschrift Psrychpsychologie [sic!]. Darunter auch Martyana.

167. Antworten Brentanos auf Fragen Martys über formale Logik etc.

168. Bemerkungen Brentanos zu einer Abhandlung Martys über synkategorematische Zeichen. Alt: 1867/68. Originalhandschrift Brentano.

169. Accidentien. Brentaniana aus verschiedenen Jahren.

170. Verschiedene Brentaniana: Unendlichkeit, Gott und Welt, Psychologisches. No 155-170 bedürfen einer genaueren Durchsicht und Ordnung.

171. Aufschrift: Anmerkungen. Brentano über Zeit, Wesenhaftes, Unwesenhaftes. 5 Blätter (Briefpapier), 5 weitere Viertel- und ein Achtelbogen. Martyskript.

172. Zur Lehre von der Wahrscheinlichkeit. Anmerkungen zu Stumpfs Schrift mit der Abhandlung von Stumpf (zwei Brochuren). Martyskript. (habe ich Kastil geliehen)

173. Brentaniana aus neuester Zeit: modus obliquus etc. 1911 oder 1912. Martyskript.

174. Brentaniana betreffend Aristoteles. Wohl 1911. Martyskript.

175. Brentaniana aus den letzten Jahren 1912 oder 1913. Martyskript.

176. Ferien 1912: Brentaniana.

177. 1912: Brentaniana.

Einige Blätter, die Biographisches enthalten, habe ich, wie schon früher auch, zum biographischen Faszikel gelegt. Vide biographisches Archiv.

178. Ferien 1913: Brentaniana. Martyskript.

179. Historisch-Kritisches über Causalität. Brentaniana aus verschiedenen Jahren. Martyskript.

180. Varia, insbesondere über Christentum, aber auch anderes; sehr vieles von Brentano, noch zu untersuchen.

181. Zu James. Notizen nach Brentano. 11 Martyblätter.

182. Aufschrift: Geschichte der Philosophie und Religionen. Enthält aber Diverses über alle möglichen Frage. Martyskript.

183. Intensität. 2 Martyblätter. 
184. Zur „Zukunft der Philosophie“. Exzerpt?? 10 Martyblätter.

185. Zu „Aristoteles“. Das Meiste ex 1910.

186. Ferien 1899: Geschichte der Philosophie, insbesondere Leibniz. Martyskript.

187. Ein Helmholtzfaszikel. Nicht festgestellt von wem; einiges sicher von Brentano.

188. Ein Faszikel mit der Aufschrift „Psychologie“ (im Allgemeinen). Martyskripte aus verschiedenen Jahren, ebenfalls das Meiste Ferialnotizen.

189. Ferialnotizen und Sonstiges aus verschiedenen Jahren, das vor und hinter No 188 lag. Ungeordnete Martyskripte, auch hier das Meiste Brentaniana?

190. „Classifikation der psychischen Phänomene“. Ex 1205.

191. Ein Faszikel „Religionsphilosophie“. Enthält zuerst Exzerpte aus Nietzsche, die von Marty herrühren, und wohl auszuscheiden sind.

192. Zur Religionsgeschichte, darunter Versehen der christlichen Moral I und II.

193. Christentum und Religionsphilosophie. 1898. Martyskript.

194. Zur Religionsphilosophie. Martyskript.

195. Über Religionsphilosophie und Kirche. Martyskripte.

196. Über Religion. 1905. Ferialnotizen, wie auch nahezu alles Vorhergehende.

197. Religionsphilosophisches und anderes aus verschiedenen Jahren. Altes und neues, darunter mehrere Blätter aus 1902 und ganz altes. Martyskript.

198. Zur Theodizee. Martyskript.

199. Metaphysik (Theologie). Ex 1902, 1899 und früher.

200. Weitere vier Martyskripte, teilweise Literatur, wohl von M.

201. Betrifft Apperzeption. Einige Blätter aus Marty, ein Blatt aus einem Briefe Brentanos, dann ein Brouillon eines Martybriefes.

202. Über ens rationis ([?]rationalisten). 9 Martyseiten.

203. Ferialnotizen ex 01 und aus späteren Jahren. Einige Blätter von Marty selbst mit Aporien und Einwänden und Bemerkungen über die Genesis der Lehre.

204. Notizen über Induktion, Wahrscheinlichkeit etc. Causalgesetz, Logisches.

205. Brentanos Notizen zu Stumpfs Aufsatz über Wahrscheinlichkeit mit beiden Abhandlungen Stumpfs aus der bayrischen Akademie der Wissenschaft (hat Kastil in Innsbruck ausgeliehen).

206. Bemerkungen über Ähnlichkeit. Zu einem Aufsatze von Marty, Vorarbeiten zum Kongressbericht (Abdruck liegt bei).

207. Definition. Krausstenogramm nach Brentano-Fragment. 1908?

208. Hypothetisches Urteil. 4 Martyblätter. Scheint von Brentano. 
209. Vorschläge zur Reform des Mittelschulunterrichts. 2 und ein halbes Blatt. Martyskript.

210. Brieffragmente (Kopien!). Darunter auch ein Blatt, wo Brentano zu Martys Ursprung der Sprache Bemerkungen über das sprachlose Denken macht.

211. Ein Faszikel Notizen nach Brentano über die verschiedensten Gegenstände (gelber Carton?). Ästhetisches, Ethisches, Kunst. (Hat Kastil ausgeliehen zum Zwecke der Durchsicht.)

212. Ein starkes gut geschriebenes Heft über das Christentum, Prüfung seiner Argumente. (Hat Kastil mitgenommen zum Zwecke der Feststellung der Autorschaft.) Kaum von B. selbst.

213. Rechtsphilosophisches. Sieht Dr. Engländer durch.

214. Eine Abhandlung über Induktion. (= No XIX Eisenmeier) Juli 1906. Mit dazugehörigen Martynotizen.

215. Eine Abhandlung über Kausalität, Kausalgesetz. Juli 1906.

216. Varia Mixta $(M+B)$ über Ästhetik und Kunst. Ähnlich wie No 211 auch Martyano[sic!]

217. Drei blaue Hefte Notizen und Abschriften aus Zürich 1917 und ein Wachsleinwandheft mit Notizen und Abschriften aus Zürich teilweise identisch mit den Machinoskripten, die in Zürich und Innsbruck angefertigt wurden (Gottesbeweis, Unsterblichkeit, Continuum etc.) sofern nicht schon kopiert abs

218. Die dogmatische Theologie von Heinrich mit zahlreichen Randbemerkungen von Brentanos Hand (auch Marty?). 1874 u.f.

219. Eine stenographische Niederschrift (Nachschrift) des Kollegs Brentanos über Ethik und das Dasein Gottes. Wiener Vorlesungen. Bleistiftstenogramm, teilweise mit Tinte überschrieben. Von Kastil seinerzeit durchgesehen, unvollständig.

220. Vier Kollegienhefte (Bücher!) von Marty nach Brentanos Vorlesungen 1869 u. f. und zwar Logik, Psychologie und Geschichte der Philosophie. Ordentlich geschrieben, aber stark beschädigt durch Herausreißen ganzer Partien. Die Psychologie relativ am vollständigsten, in schwarzem Einband (im Schreibtisch aufbewahrt).

221. Die in Zeitschriften aufbewahrten veröffentlichten Abhandlungen Brentanos, soweit sie mir bekannt und zugänglich. Manches ist auch anonym erschienen.

NB Die Briefe Kastils an Marty, an mich enthalten auch Wissenschaftliches und Biographisches, ebenso meine an Marty und die von Marty an mich. Letztere sind sub XX verzeichnet bei biograph. Archiv. 
Die Briefe an Ehrenfels! Die zahlreichen Briefe an andere Persönlichkeiten wären zu sammeln!!! An Schell z. B. Boltzmann. Stumpf hat [?] 130 Briefe.

NB!! Hiezu kommt das Martyarchiv, sofern es noch Brentaniana enthalten sollte, die ich noch nicht als solche festgestellt habe, insbesondere die Kollegien Martys, die ja vielfach die Lehre Brentanos getreu wiedergeben, insbesondere die aus früheren Jahren!! Und hier wieder die über Metaphysik, Erkenntnistheorie, Logik und Psychologie. In späteren Jahren finden sich Abweichungen betreffend die Inhalte etc. etc. Zeit, Raum, Causalitätsgesetz. Die früheren sind daher zur Feststellung Brentanoscher Lehren besonders wichtig. Diese Kollegien sind zum Teil im Martyarchiv eingeordnet und registriert, teils aber in einer Anzahl Schachteln (Cartons) ungeordnet, wie sie in Martys Kasten etc. beieinander lagen.

\section{Biographisches Archiv}

I.a Kurze Biographie und Materialien zu einer Biographie Brentanos bis 1906 (Marty).

I.b Biographische Notizen Martys seit 1869, die ebenso für Martys wie für Brentanos Biographie bedeutend sind. 55 paginierte Martyseiten.

II. Diktate Martys über Brentanos und Martys Leben, über meinen Wunsch bereits im Jahre 1895, beim Spazierengehen niedergeschrieben auf Grund von No I. 26 Seiten von mir (Kraus) geschrieben, recte 28 S., 4 und eine Viertelseite von Kastil und 13 weitere Blätter von mir. I und II bezieht sich auf den Wendepunkt in Brentanos und Martys Leben. Beiliegend die Thesen anläßlich der Habilitation in originali (Brentano) und eine Dispens für Marty, die ihm verbotene Bücher zu lesen gestattet.

III. Biographisch wichtige Blätter aus verschiedenen Martyfaszikeln zusammengelegt, z. B. Brentanos Studiengang, z. B. über Döllinger.

Fragen an Brentano bei seiner theologischen Prüfung und seine Antworten.

Allerlei auf seine Familie Bezügliches.

Daß Hertlings Schrift über den Begriff der Eins bei Aristoteles die Gedanken von Brentano hat (die guten nämlich); über Christian und Clemens, über Fügungen in Brentanos Leben, über die Entstehung der mannigfachen Bedeutung des Seienden, über Brentanos Gedächtniseigentümlichkeiten. Seltsame Erzählungen Prof. Schegg Kaplan Stier, 
politische Ansichten [über] Bismark-Preußen, ein Brief an Gautsch (Brentano überreicht ihm die Zukunft der Philosophie).

IV. Tagebuchblätter von Kraus aus dem Jahre 1894 und folgende. Zum Teil leserlich, zum Teil Bleistiftstenogramme auf Brentano und Marty bezüglich.

V. Marty über seine Audienz bei Madeysky und die Wiener Professur. Die Biographie Brentanos ist mit jener von Marty vielfach so verknüpft, daß eine Scheidung der Materialien nicht praktisch, ja nicht möglich ist.

VI. Dennoch ist das Büchlein über die italienische Reise, die Marty und Brentano gemeinsam unternahmen, besonders auch für Brentano interessant und darum hier eingereiht. 1876/77 italienische Reise 1879- (No 5 frühere Indizierung der Tagebücher).

VII. Ebenso No 14 der Martybiographie in dem Studienjahr 1886/87 (Nb die übrigen Tagebücher bezw. Notizbücher Martys sind gesondert aufbewahrt und als solche kenntlich gemacht) (gesonderter Index über Martybiographie).

VIII. Gedruckte Nekrologe und Notizen anläßlich des Hinscheidens Brentanos.

IX. Faszikel in blauen Deckeln enthält verschiedenes Material für eine Brentano-Biographie und eine Geschichte der Schule: viele Zeitungsausschnitte, Tagebuchblätter, Aufzeichnungen wichtiger Ereignisse seit Anfang meiner Studien.

X. Enthält mehr auf meine eigene Entwicklung Bezügliches, doch auch solches, was für die Geschichte der Prager Schule interessant; verschiedene Materialien seit Studienbeginn.

XI. Faszikel enthält eigene Aufzeichnungen und Notizen, auch Diktate aus Schönbühel und Florenz seit 1893, dazu eine Schachtel mit Notizbüchern, noch zu ordnen und abzuschreiben. Zur Entwicklung der Lehren interessant. Meist während der Spaziergänge und Gespräche stenographiert und aufgezeichnet.

XII. Umfangreicher Martyfaszikel auf die Geschichte der Prager Schule bezüglich. Viele Briefentwürfe, insbesondere Gutachten an Fakultät und Minister, und Sonstiges auf die verschiedenen Fakultätskabalen Bezügliches. Dazu

XIII. ein Carton mit Briefentwürfen etc. etc. 6 im unteren Teil des Kastens aufbewahrt.

XIV. Eine Mappe mit Gedichten und Rätseln, unveröffentlicht und veröffentlicht. Originalhandschriften und Abschriften.

XV. Photographien von Brentano, Marty und deren Familien. Hiezu auch zahlreiche eigene Aufnahmen, darunter stereoskopische, und Diapositive. 
XVI. Briefwechsel Brentano-Marty und zwar Briefe Brentanos an Marty seit 1869, diese werden registriert und ein kurzes Inhaltverzeichnis, mit Index wird angelegt.

Einen Teil bearbeitet Kastil. Von 1869 bis 1889. Hiebei auch Briefe von Ida Brentano an Marty und der Mutter Brentanos an Marty.

XVII. Briefe Brentanos an Kraus seit 1893. Diese sind nach Jahren geordnet. Index und kurzes Inhaltsverzeichnis wird angelegt. Hiezu auch Briefcopien von Kraus an Brentano aus den letzten Jahren.

XVIII. Zahlreiche Briefe verschiedener Personen an Marty. So seiner Schüler Kastil und Kraus. (Eisenmeier hat die seinen zu sich genommen.) Briefe Stumpf an Marty, Mach, Willmann, seine Familienangehörigen, sofern sie nicht von Pfarrer Marty vernichtet worden sind. Und so weiter. Die Briefe befinden sich im Bücherkasten in Päckchen und enthalten Interessantes zur Schulgeschichte, insbesondere die von Stumpf.

XIX. Sämtliche Tagebücher und Notizbücher Martys. Hiezu ein eigenes Verzeichnis: Einiges daraus ausgesondert und sub VI, VII, I und V oben verzeichnet.

XX. Briefe Martys an mich, und umgekehrt. Nach Jahren geordnet.

\section{Von Prof. Kraus im Sept. 1920 aufgenommenes Verzeichnis der Schriften meines Vaters, die sich in Zürich befanden (die doppelte Nummerierung entspricht zwei versch. Aufbewahrungsstellen, das zweite Verz. bezieht sich auf die in einer Kiste enthaltenen Manuskripte}

\section{I. (rote Nummern)}

Index. Franz Brentano

I. $\quad$ Fehlt die Bezeichnung. Scheint ein Logikkolleg nach 1885.

II. Monismus Positivismus, Skizze, Kolleg. - Lehre von den Relationen. 1899, Palermo. - Abstraktion., 1899 Palermo ausgearbeitet Brief. - Ferner Brief an Faggi über Optimismus, ausgearbeitet, druckfähig, aber ältere Anschauungen. - Zum Parallelenproblem (ausgeschieden; liegt bei LII, II. Index) $)^{4}$ und psychologische Aphorismen, Schönbühel 1889.

III. Broschüren von Hillebrand, Hering zur Farbenlehre, darauf bezügliche Briefe von Marty, Hering u.a. - Stumpfs Gemütsbewegung mit Randbemerkungen und Originalbriefentwurf Brentanos an Stumpf. - Zeit-

4 Kursiver Text markiert handschriftliche Ergänzungen vermutlich von Kastil. 
abhandlung, Entwurf. - Diverses. - Psychognosie, Entwurf und Psychologie, Diverses. -

IV. $\S 63$ (4 Phasen). 1 „Waschzettel“ für Zeitungen. -

V. Über die Wechselwirkung der Naturkräfte, Vortrag, gehalten in Würzburg und Wien. - Über Funks Zivilisation. - Verschiedene Entwürfe für Seminarbesprechungen, u. zw. über Cartesius 1888/89, über Laplace ausführlich. - Parallele (zu LII). - Betrachtungen beim Austritt aus dem Christentum. Briefentwürfe an Minister. - Brief an Berger? - Mitteilung an die Akademie über Intensität, ex 1879/80. -

VI. Aus der Studienzeit. -

VII. Cantor (Mathematik Schriften von Cantor und Briefwechsel darüber mit Enriques.-

VIII. Unvollkommene Entelechie (Aristoteles) Diktat 13/III 07. - Vom Dasein Gottes 1891/92. - Erkenntnistheorie (Diktat 37 Seiten). - Wissenschaft Diktat 20. XI. 07. - „Die Lehre von derKlassifikation 7/XII/07 und über Begriffe und Klassifikation der Wissenschaften 28/XI/O7. Zu kopieren! Nebst Inhaltsangabe.

IX. Aus den Jahren, wo Brentano ein negatives Vorstellen lehrt, überholt, wohl vor 1908.-

X. $\quad$ Über Martineau Ethik 1907. - Zu kopieren. - Scheint selbständige Abhandlung.

XI. Rückblick auf meine Artikel über ein optisches Paradoxon. Nachsehen in Ebbinghaus, ob gedruckt. - (leserlich, druckfähig)

XII. Psychologie 1888/89. - Philoshie 1893/94 Kolleg. - über zeitbewegende phil. Fragen soziale Frage vide XVIII. 1893/94. Positivismus \& Monismus.

XIII. Logik. 92 Blätter. - Winter 1878/79 und 1884 mit ausführlicher Inhaltsangabe, leserlich. Von den Sophismen und ihrer Anwendung auf polit. Gebiet. 3. Mai 76. 101 Seiten sehr schwer zu lesen.

XIV. Substanz. Entwurf, vor der ersten Augenoperation. - Wesenloses, später als Fiktion verworfen. Wichtig. für die Genesis der Lehre, nicht ganz leicht zu lesen.

XV. Sehr wichtig. Entwurf zur Denkschrift der deutschen Bischöfe gegen die Unfehlbarkeit ex 1869, vide Kraus Brentano Seite 8, dabei ein Brief von Hefele ex 1870. - Zuschrift des Dekans an Brentano Zulassung zur Habilitation. Habilitationsthesen gedruckt mit Randbemerkungen, Übersetzung dieser Thesen.

XVI. Diverses, auch ein Theaterstück. - Die 3 größten Wunder; zu kopierende Prosastücke über die Schönheit von Florenz. 
XVII. Ontologie. - Natur des Punktes eigenhändig. - Vom Vorstellen. - Über formale Logik. - Substanz und Akzidenz, Zahl. Zur Kategorienlehre. Substanz. - Von der Substanz. - Erkenntnis. - Aus späteren Jahren zu kopieren.

XVIII. Ibsen als Moralist, besteht lithographische Abschrift. - Brief von Brandl, Saar. Über das Schlechte. Sozialismus und soziale Frage. Schlagworte aber ausgezeichnet. Vide XII [?] - Wahrheit 1887/88. Auch lithographiert 1889 (hat auch Kraus). - Über Schellings Philosophie 17/XII. 89 (66).

XIX. Das Schlechte als Gegenstand. - Ästhetisches. - Delboeuf Megamikros Brief Brentanos (kopieren). - Lithogr. Abhandlung nicht von Brentano. Continuum Diverses. - Varia Diverses. - Was ist Philosophie? -

XX. $\quad$ Psychognosie Kolleg 1890/91. - 389 Seiten. Gut zu lesen! Kann publiz. werden vide $X X V$.

XXI. Anmerkungen zum Intensitätsvortrag. - Ungeordnete Aphorismen. Ohne Bezeichnung. - Vorwort zu den Untersuchungen über Sinnespsychologie. - Rezensionen etc. Ebbinghaus. - Römischer Vortrag.

XXII. Ältere Transzendentalphilosophie und Ontologie, nur teilweise geordnet.

XXIII. Psychognosie, leserlich und anderes Psychologisches, eigenhändig. $\mathrm{Zu}$ kopieren. -

XXIV. Geschichte der Philosophie. - Kastil hat eine Abschrift zum mindesten der Alten! Zu redigieren.

XXV. Descriptive Psychologie 1887/88. - Kann veröffentl. werden, relativ druckreif (vide XX).

XXVI. Wesenhaftes und Unwesenhaftes (Synechologie Palermo (6 Hefte). Zum Grün-Vortrag. Brief an Amato 26. April 1900 „Meine Tage in Palermo sind gezählt“ (existiert noch einmal). - Andere Briefe über naturphilosophische Fragen an Breuer? - Hymne an Anaxagoras. - Lieben und Wünschen. - Diverses.

XXVII. (Briefe an Vaila dasterer Zeit. - Vortrag Gottesbeweis übertragen in den Index II. 28 Blätter, gut! Kopieren! - Diverses. - Briefe von Studierenden.

XXVIII. Unsterblichkeit, Vorlesungen, leserlich zu publizieren mit den späteren Nachträgen. - Gespräche mit Müller über Gott und Seele. - Materialien zu Grün-Vortrag, zu Genie-Vortrag etc.

XXIX. Zur Methode aristotelischer Studien, zur Methode der historischen Forschung 1888 ist kopiert in Prag. - Moderne Irrtümer über die Gesetze des Schliessens 1890/91. - 
XXX. Ausgewählte Fragen aus der Psychologie $u$. Ästhetik 1885/86. Geschrieben, leserlich. -

XXXI. Scheidung von descr. und gen. Psychologie. - Brief über Cantor. - Zur Grössenlehre. Über die Zahl! (wichtig kopieren! Mappe [?])

XXXII. Praktische Philosophie 1879. - Kritik Herbart's. -

XXXIII. Verschiedenes u. zw. a) Leitzettel für ausgewählte psychologische Fragen. - b) Leib und Seele, Materialien. - c) Altes Psychologiekolleg, Blatt 85-137 und 74-77. - d) Dasselbe, Blatt 67-74. - c) Psychologie Kolleg Wien 1874, beginnend mit Blatt 5-19. - f) Ausgewählte Fragen, 15 Seiten. - g) Psychologie, Blatt 1-10, sodann 66, § 5, 66, 1, 66, 8. - h) Psychologie 1879/80, einige Blätter und Diverses. - i) Abermals Psychologiekolleg, Blatt 29-124. - Von der Freiheit, gehörig zu den Untersuchungen über die Unsterblichkeit aus Würzburg, später ausgeschieden, in derselben Schleife Richtungen in der Psychologie, ferner Psychologie aus der ersten Redaktion, ausgeschieden und von den psychischen Phänomenen und ihren Gesetzen. -

XXXIV. Verschiedene alte Manuskripte in Schleifen mit der Überschrift: a) metaphysische Fragen, Ontologie, Ursache, Qualitäten der wirklichen Körper. - b) Synechologie. - c) Aus einem alten Logikkolleg, über Schlüsse und Aussagen. - d) Sinnespsychologie, ein Brief von Marty an [?] - e) Diverses. Brief über das individualisierende Moment ex 91 [01?], Energie[?] der Zeit (veraltete Redaktion, Brief über Irrtümer beim Schließen an Ueberhorst Innsbruck [?]. - 4 - f) Niederschriften, wohl nach Kollegien aus der $\mathrm{t}[\mathrm{h}]$ eologischen Zeit.

XXXV. Materialien zu den Untersuchungen zur Sinnespsychologie.

XXXVI. Materialien zum optischen Paradoxon.

XXXVII. Eine Mappe mit allerlei Papieren, besonders Gedichten, Brochuren, Brentanos Antwort auf die Rundfrage nach der Berechtigung des Selbstmordes aus der deutschen Zeitung Wien 6 September 1893 ferner lithographiertes Schriftstück (Vorlesung?) über die phantastische Gesichtserscheinung (Sonnenerscheinungen) von Johannes Müller, Colleg ex 1836 dürfte selten sein, aufzubewahren.

\section{II. (blaue Nummern)}

Franz Brentano II. Index.

I. Ein Exemplar Aristoteles Lehre vom Ursprung des menschlichen Geistes Leipzig 1911 mit drei eingelegten Ergänzungen. - 
Ia. Konvolut über die Lehre des Aristoteles von der Ewigkeit des Geistes, Zeller, Kritik Florenz 1911.-

Ib. Konvolut Brouillons zu Creationismus. -

Ic. Zum Creationismus März 1909. -

Id. De generatione animalium, II 3. Gang des Kapitels. -

Ie. Über die Platon zugeschriebene Lehre, dass die Seele schon im Samen Aufnahme findet. -

II. Ein Exemplar von Aristoteles und seine Weltanschauung, mit Zusätzen versehenes Exemplar, Quelle und Meyer Leipzig 1911. - Wichtig für Neuauflage. - Dabei ein Brieffragment an Schneider Gera über Platon. -

IIa. $\quad$ Altes Manuskript, Seite 14-56. -

IIb. Altes Manuskript (hieraus sind einige Seiten zu benutzen). -

IIc. Vorarbeiten. -

IId. $\quad$ Erste Redaktion. - Diverse Dispositionen, Leben. -

IIe. Ausarbeitung. - (Interesse, Schwierigkeit, gegen Zeller, Elser und Rolfes, Gomperz). -

IIf. Besondere Schwierigkeit des Aristoteles. -

IIg. Methode. -

IIh. Plan zur Methode. -

IIi. Pläne, Verfahren, Gruppen. -

IIj. $\quad$ Locker aneinander gereihte Punkte zu V, VII, VIII und IX. -

IIk. Zur Metaphysik des Aristoteles Gehöriges, nach dem alten Plan zu IX. -

IIl. $\quad$ Aristoteles analytica. -

IIm. Zeller, frühere Redaktion. -

IIn. Zeller, scheinen Seiten zu fehlen. -

IIo. Z Zweites Buch der Ausarbeitung VII. -

IIp. $\quad \mathrm{Zu}$ VII nach dem alten Plan, Alexanders Kommentare, die missverstandenen Stellen. -

IIq. $\quad$ Metaphysik, X. Kapitel Lambda. -

IIr. Diverses, Buch VII, einzelne Sätze, Synonymie (7. Juni), Sätze aus der Metaphysik XII. Buch zu de anima. -

IIs. $\quad$ Aristoteles über das Gesetz der Synonymie. -

IIt. Angestrichene Stellen aus Aristoteles' Schriften. -

III. Kritik über Zellers Philosophie der Griechen, 3. Auflage. Wichtig. 4 Abteilungen a, b, c, d. 1909.

IV. Aristoteles 25. VII. 07, Erkenntnis des durch sich Notwendigen. -

Va. Verschiedenes, u. zw. Synonymie und Analogie. - 
Vb. Aristoteles Verhältnis zwischen Empirismus und Nativismus. -

Vc. Übersetzung von Stellen aus Aristoteles. - 1907.

Vd. De interpretatione. -1909.

Ve. De anima. - 1910.

Vf. Analytica posteriora, Definition, Dezember 1909. -

Vg. Analytica posteriora. -

Vh. Metaphysik Lambda, Gedankengang. - 1910. Vergleich der Politik u. Metaphysik; wichtige Ordnung d. Politik.

Vi. $\quad$ Von der Bedeutung des Seienden. -

Vj. $\quad$ Zu Kapitel Lambda, Übersetzung, Inhaltsangabe, Aporien. -

Vk. Aporien, 3. Fassung. -

Vl. $\quad$ Aporien, Fortsetzung, 1 u. 2 zu Lambda X. -

Vm. Physicae auscultationes, wichtigste Frage aus der Physik, Auszug, Inhaltsangabe. -

Vn. Naturalia parva, Januar 1910. -

Vo. Bemerkungen zu Aristoteles de partibus animalium. -

Vp. $\quad$ Ethica ad Eudemum, September 1909 mit Briefstelle an Marty. -

Vq. $\quad$ Aristoteles Analytik, Bemerkungen. -

Vr. De Gen. An. II, 3 737a 7. -

Vs. Zur aristotelischen Kategorienlehre 1909 September. -

Vt. Nikomachische Ethik. -

Vu. $\quad$ Aristoteles' Lehre vom Guten. -

Vv. Abhandlungen über das Gute und die aristotelische Ethik. -

Vw. Nikomachische Ethik, Inhaltsangabe. -

Vx. Nikomachische Ethik, Begriff der Ethik, 25 Halbseiten. -

Vy. Zur nikomachischen Ethik. -

Vz. Zur nikomachischen Ethik. -

V1. Bücher von der Freundschaft. -

V2. Zur Ethik. -

V3. Zur Ethik. -

V4. Ethik, Schönbühel 1910. -

V5. Ethik, Schönbühel 1910. -

V6. Zur Ethik. -

V7. Nikomachische Ethik und Politik des Aristoteles. -

V8. Politik des Aristoteles, Auszug und Inhaltsangabe. -

VIa. Aristoteles, Ontologie 1908. -

VIb. Zur aristotelischen Theologie, Januar 1909, Methodisches. -

VIc. Sätze, welche für Aristoteles weithin massgebend sind. -

VId. Aristoteles' Lehre vom Ursprung unserer Ideen ex 1908 April. - 
VIe. $\quad \mathrm{Zu}$ Aristoteles. -

VIf. Gott sorgt vor. -

VIg. Zur Theologie des Aristoteles. -

VIh. Aristoteles, wo er zu früheren Ansichten Stellung nimmt. -

VIi. Aristoteles' Lehre vom Wirken und Leiden. -

VIj. $\quad$ Zu Aristoteles' Metaphysik ex 1908. -

VIk. Aristoteles' Physik. -

VIl. Aristoteles' Wiedergabe fremder Meinungen. -

VIm. $\quad$ Aristoteles und Leibniz. -

VIn. $\quad$ Chronologie der Werke des Aristoteles. -

VIo. Verschiedenes zu Aristoteles. -

VIp. $\quad$ Intellectus agens, materia prima, Juli 1909. -

VIq. $\quad$ Altes zur Physik und Anderes. -

VIIa. Abschriften von Briefen an Gomperz über Theophrast Sept. 1909, an Benn Mai 1910, an Tworbovsky Okt. 1909, an Rolfes Mai 1910. -

VIIb. Über Hertlings Materie und Form. -

VIIc. Briefwechsel mit Rolfes von ihm und an ihn über Aristoteles aus den Jahren 1908 und 1909. -

[Handschrift Kraus:] n.b. einiges hier nicht aufgenommen vide KrausArchiv, wo Abschr. über Theophrast wie denn überhaupt bei Kraus noch so manches enthalten ist, was hier nicht vorkommt. Hiezu wäre sein Index zu vergleichen, der weit über 400 Nummern enthält, darunter vieles von Marty Übernommenes z.B. Notizen von Marty nach Gesprächen aus den Ferien, Briefkopien an verschiedene Schüler u. Gelehrte, der ganze Briefwechsel mit Marty und vieles andere, was aus seinem Inventar zu entnehmen ist. -

VIIIa. Vorarbeiten zur Tonpsychologie, Tonelemente und Oktaven, größtenteils eigenhändig geschrieben. -

VIIIb. Grün-Vortrag, Anhang 93-147, gedruckt. -

VIIIc. Tonelemente, Vortrag, Konzept. -

VIIId. Tonelemente, Abschrift des Vortrages, gedruckt. -

IX. Anmerkungen zur Psychologie vom empirischen Standpunkt (Klassifikation der psychischen Phänomene) Florenz 1910 mit Varianten. X. Von der Verschmelzung der Töne, August 1903, Eisenmeyer-Diktat. XI. Von den Elementen der Töne und der teilweisen Identität der Oktaven, 13 Seiten.

XII. Tonpsychologisches. -

XIII. Manuskript zu den vier Phasen, Original, eigenhändig. - Epikur und der Krieg, gedruckt. - 
XIV. Optimismus und Pessimismus, eigenhändig geschriebene Abhandlung, zu kopieren, drutuähig. - Vergl. die Abhandlg. über das Schlechte und seine Vereinbarkeit mit der Allgüte Gottes.

XV. Kleine Skizzen.

XVa. Indeterminismus, 4 Seiten. -

XVb. Philosophie und Theologie, 7 Seiten. -

XVc. Zur Klassifikation der Künste, 58 kleine Seiten. -

XVd. $\quad$ Aphorismen über den Krieg, 2 Seiten. -

XVe. Vom Schlechten, 3 Seiten (metaphysisch). - zu kopieren!! wichtig

XVf. 1903 über die sittliche Vollkommenheit der ersten Ursache, Eisenmeyer-Diktat, Abschriften in Prag, Innsbruck. -

XVg. Von der Notwendigkeit einer ersten Ursache, Eisenmeyer-Diktat, Abschriften vide f. -

XVh. Von der Seligkeit Gottes. -

XVi. Vom Schlechten und seiner Vereinbarkeit mit der Allgüte Gottes (diese kleine Abhandlung aus dem Jahre 1909 findet sich nicht unter den Manuskripten. Es bestehen aber Abschriften bei Kraus, Eisenmeyer u.a.)

XVk. Kontingenzbeweis, Fragment. -

XVI. Sprechen und Denken, August 1905, Eisenmeyer-Diktat. - Kopien in Prag. -

XVII. Von der Tierseele, August 1903, Eisenmeyer-Diktat. - Kopien in Prag. vide XXXII

XVIII. Von der Erkenntnis, August 1905, Eisenmeyer-Diktat. - Kopien in Prag. -

XIX. Von der Größe ex 1893. Kopien in Prag. -

XX. Von der Behauptung der Willkür der ersten Annahmen bei der Bestimmung der Wahrscheinlichkeiten. Kopien in Prag. -

XXI. Von der Natur der Vorstellung, August 1903. - Abschriften in Prag. Die hierin vorgetragene Anschauung ist aufgegeben worden. -

XXII. Über den simultanen Kontrast ex 1906, 5 Seiten, zu kopieren. Abschrift dürfte Eisenmeyer besitzen. -

XXIIIa. Kein negatives Vorstellen, eigenhändig. -

XXIIIb. Vorstellung und Urteil, eigenhändig. -

XXIIIc. Vorstellung und Begriff, eigenhändig. -

XXIIId. Verneinung, eigenhändig. -

XXIIIe. Fragen, betreffend das Vorstellen, eigenhändig. -

XXIIIf. Vorstellung und Urteil, Mai 1906, eigenhändig. -

XXIV. Eigenhändige Ansätze zu Metaphysikentwürfen. - 
XV. Theologie, Fragment, eigenhändig. -

XXVI. Eigenhändige Entwürfe zu Aufsätzen über Relationen (a) psychische Beziehungen, (b) Aphorismen über Reproduktion des sinnlich Wahrgenommenen, (c) (d) Aphorismen ex 1906 über Wahrnehmung von Kontinuen, e) Aphorismen über Überlegenheit des psychologischen Wissens, zu kopieren, f) über Dass-Sätze, g) Fragment über Kontinuum. -

XXVII. a) Von der Seele, eigenhändig, 4 Seiten. - b) Psychologisches, eigenhändig. - zu kopieren

XXVIII. Verschiedene Entwürfe über psychische Phänomene, über Wirken, Ding und Kollektiv. - Relationen, Seiendes etc. eigenhändig, ältere Zeit vor 1903. -

XXIX. Phantasie m.p. ${ }^{5}$ wichtig, zu kopieren. bald

XXX. Von psychischen Synthesen, Allgemeinbegriffe, Vorstellung. - M[sk] pt.

XXXI. Gibt es ein positives und negatives Vorstellen? 1907. - Vorstellung und Urteil (Bergmann, Windelband). - Vorstellen, Relationen, ganz kurz. -

XXXII. Tierpsychologische Aphorismen. - Kurzes Mskpt, (a) die Brieftaubenfrage (Skizze) (b) Von der Tierseele (c) Brief an Utitz (d) Menschen- $u$. Tierseele.

XXXIII. Vom Denken m.p. und ens rationis, ausführliches Manuskript, zu kopieren.

XXXIV. a) Kritik der hergebrachten Intensitätslehre, b) zur Lehre von der Intensität m.p., c) uns Größe der Abstände, Diktate aus dem Jahr 1907. (Dürfte zu den Untersuchungen zur Sinnespsychologie gehören). Nachträge zu kopieren c (Zeit) gleich zu kopieren.

XXXV. $\quad \mathrm{Zu}$ Briefen an Marty über Inhalt, Wahrheit, negative Vorstellungen (Etappen auf dem Wege zum Modus obliquus, teilweise überholt, sehr instruktiv). - 1907.

XXXVI. Diktate zur Lehre von den Universalien, 17. Mai 1908, b) Wesen, Substanz, Suppositum, Essenz, c) über seiend, wahr und gut, 3. Mai 1908. d) Seiend nennen wir, 4. Mai 1908. - e) von den Äquivokationen, 2. Mai 1908, f) von den Relationen , 13. Mai 1908. - Wichtige Vorarbeiten zum Anhang zur Klassifikation der psychischen Phänomene, zu kopieren. -

XXXVII. a) Kapitel-Überschriften zu einer Metaphysik nebst Vorwort zu einer Metaphysik, skizzenhaft. - b) Weisheitslehre, Mai 1908, Übersicht und

5 m.p. = manu propria, eigenhändig. 
Beginn der Ausführung. - c) Metaphysik, Kapitel-Überschriften und Weisheitslehre-Überschriften. - Später zu kopieren.

XXXVIII. Mehrere Überschriften zur Ontologie aus verschiedenen Jahren. XXXIX. Ausführliches Diktat über Terminologie, zu kopieren. - aristotelisch XL. $\quad$ a) Sprache, Fragment, zu kopieren, m.p. 1905. - b) die Sprache 1906, zu kopieren. - c) Diktat über die Sprache, zu kopieren. - d.) Einteilung der Sprachwissenschaft. - e.) Von der Sprache, zur Sprachphilosophie. -

XLI. a) Der Name existierend und seine Äquivokationen, 1904, Original hat Kraus. - b) Logisch wichtige Ausdrücke. - c) Namen, April 1907, Diktat. - später zu kopieren.

XLII. a) Von der Prädikation, m.p. -b) Einfache und zusammengesetzte Urteile, m.p. - c) Vom hypothetischen und disjunktiven Urteil, Diktat. - d) Vorstellung und Urteil, eigenhändig, aufgegeben, historisch interessant, etwa 1904. -

XLIII. Fragment m.p. über Erkenntnistheorie, Ontologie 1905?, Reales. 1906.

XLIV. a) Psychologische Skizze (,unter einer menschlichen Seele verstehe ich eine Substanz“) 22 Blätter, m.p. besteht Marty Kopie? - b) Zur Frage nach der negativen Wahrnehmung, Mai 1904. - (є) Die Brieftaubenfrage, 1904) (bei N XVII) - d) Vom Seienden. - e) Vom ens rationis. - f) Von den psychischen Tätigkeiten und Beziehungen, Fragment. Mai 1904 - g) Vom Denken, 6 Skizzen. -

XLV. Vom Nominalismus gegen Guastella, Palermo 1900 m.p., Abschriften bei Kraus, Eisenmeyer u.a. - zu kopieren!

XLVI. Megethologie, verschiedene eigenhändig geschriebene Entwürfe, darunter auch ein Exzerpt aus Bolzanos Paradoxien des Unendlichen, ferner Kapitelüberschriften, ferner skeptische Angriffe auf die Megethologie. -

XLVII. Von der Größe (groß nennen wir etwas, insofern es größer oder kleiner sein kann als ein anderes) m.p. fragmentarisch. -

XLVIII. Entwurf einer Abhandlung vom Unendlichen, Skizze des Gedankenganges. -

XLIX. $\quad$ Entwurf einer Größenlehre und Synechologie, 54 Seiten, 81§, m.p., zu kopieren. -

L. Manuskript über Mächtigkeitslehre. -

LI. Verschiedene Skizzen, Entwürfe, Inhaltsangaben zur Mächtigkeitsund Größenlehre, zur Philosophie der Mathematik. - (Briefentwurf an Kraus) 
LII. Über den Ursprung der mathematischen Erkenntnis, m.p. 83[?] Seiten (die Frage nach dem Charakter bis ... keinem Anstand unterliegt). - b) Zum Parallelenaxiom. - c) Originalbrief über dasselbe Axiom, zu kopieren. -

LIII. a) Woher unsere Raumvorstellung? 17 Doppelseiten, zu kopieren. dazu 2 Blätter ex 1909. - b) Ursprung der Raumvorstellung, Entwurf (empirischer Ursprung ... Differenzen von verschiedener Gattung seien. kopieren! - Gleichzeitig geht ein Brief ab. (Gegen Stumpfs Heterogenität unserer Raumanschauungen.)

LIV. a) Vom Ursprung der Raumvorstellung, 5 Doppelseiten, etwa 1906. - b) Vom Sinnesraum, Abhandlung, Diktat, druckfähig, jedoch nicht definitiver Standpunkt. - c) Weitere Skizzen zur Raumlehre. - d) Empirismus, fragmentarische Abhandlung, m.p. - a), b), d) zu kopieren. -

LV. a) Fragmentarisches Manuskript über Kontinuum. - b) 1) Teleiose, 2) Lobatschevski 1909, 3) Apodiktizität Diktat. - c) Plerose, 2 Blätter. - b 3 (Apodikt) zu kopieren.

LVI. Zur Lehre von der Zeit a) Manuskript und Diktat „Was ist Zeit?“ - b) Zur Lehre von der Zeit, Diktat, 2 kleine Heftchen I und II. - c) Fragmente zur Zeitlehre. - d) Alte Skizze zur Zeit. - e) Urbach-Briefe zur Zeit. - f) Diverse ältere Skizzen zur Zeit. - g) Von der Zeit, Studien, Florenz 1899 ... - a) und b) zu kopieren. - später!

LVII. a) Einwände gegen die Temporalmodi. - Manuskript, zu kopieren. - b) Brief an Eisenmeyer über Raum, 15 Seiten, Anfang fehlt. - c) Brief an Marty über Zeit aus dem Jahre 1906. - d) 4 Seiten über Relation in Zusammenhang mit Eisenmeyers Bestimmung der Helligkeit. - f) 4 Seiten gegen Meinongs Annahmen, Entwurf einer Erwiderung für Marty, zu kopieren. -

LVIII. a) Kritisches Manuskript über Poincaré, Kontinuitätslehre. - b) Manuskript, Aphorismen zu P. La valeur de la science. - c) detto, zu kopieren. - 1900? (Vgl. Kritisches zu Mach)

LIX. $\quad$ a) Philosophie und Philosophen, Fragment. - b) Metaphysik, Fragment 9 §. - c) Kategorien-lehre, Fragment, 7 §. - d) Bleistiftdiktat, Seite 10-22 über Kontinuum, Anfang fehlt. - e) Diktat über Kategorien aristotelisch in Schleife. - f) Die Frage über Ganzes und Teil, Original, Bleistiftskizze, fragmentarisch. -

LX. a) Das Seiende (Seite Alpha bis Gamma). - b) Eine drehende Kugel von einer ruhenden substanziell verschieden, sinnliche Wahrnehmung zeigt nicht Individuelles, zu kopieren, (historisch) wichtig. - c) Substanz, 17 §. - d) Es ist unmöglich, dass wenn nichts sich ändert, irgend 
etwas eine Bestimmung erhält oder verliert, relative Bestimmung, denominatio extrinseca. - historisch wichtig.

LXI. a) Fragen zur Metaphysik, Diktat, Katergorienlehre, Diktat. - b) Wer denkt, nimmt sich selbst wahr, 12 §. - c) Ding, Gegenstand, Diktat, überholt. - d) Aporien, wenn ein Satz unmittelbar einleuchtet, bedarf es einer Zeit zwischen dem Denken und dem Einleuchten ... nein. Was sich selbst erhält, endigt kontinuierlich und beginnt wieder, zu kopieren, wichtig. -

LXII. Vom Objekt, Feber 1906, Diktat, 15 Seiten (Was kann Objekt sein?), zu kopieren. -

LXIII. Das Schöne mit Beziehung auf Kant, Schiller, Heine, Ostern 1906. $z$ u kopieren bald. - b) Vom Schönen, Dezember 1906 (Wenn wir ein Mädchen schön nennen). - c) Klassifikation der Künste

LXIV. Erkenntnislehre, Diktat, Fragment, zu kopieren. - im Anfang skizzenhaft

LXV. $\quad$ a) Weisheit, Metaphysik, Skizze, Diktat, 1908? - b) Dasselbe, Diktat 1908? - c) erste Philosophie oder Theologie, Übersicht, 1900. -

LXVI. Ungeordnete Papiere über Weisheit, Gegenstand etc., m.p. -

LXVII. Gott und Welt, Diktat, Kopien existieren bei Kraus Eisenmeier u.a. ein eigenhändiger Zusatz ist nicht kopiert.

LXVIII. Religionsphilosophie. - a) Gliederung des ersten Kapitels, 14 §, Diktat. - b) Scheint Kritik der christlichen Lehre, teils eigenhändig, teils Diktat, dürfte in den christologischen Abhandlungen berücksichtigt sein, jedenfalls wertvoll. - c) Von den Schriften des Neuen Testaments, Diktate in Schleife, also zusammengehörig. - d) Pascal (Ausgeschiedenes) in den christologischen Abhandlungen verwertet. -

LXIX. Religionsphilosophisches a) Infallibilität. - b) Entwurf einer Religionsphilosophie. - c) Religion. - d) Religion der Inder. - e) Augustinus, Exzerpt. - f) Über Religion, fehlt $\S 1$ und 2. - g) Infallibilität, Diktat. h) Kemmerich, Prophezeiung. - i) Skizze einer Religionsphilosophie. - j) Modernismus, Skizze. - zu kopieren ist hiervon besonders a), d), g), (Diktat). Alles interessant. -

LXX. Studien über Thomas von Aquin, auf einen Artikel in der „Zeit“ bezüglich, auf den sich auch Briefentwürfe in anderen Faszikeln beziehen, Entwurf zum Artikel in der Neuen Freien Presse. -

LXXI. Charakterisierung Pascals. - Zu kopieren. -

LXXII. $\quad$ Ein Entwurf zu einem Essay über das Weib. - Zu kopieren. -

LXXIII. Zur Naturphilosophie, a) über Auerbach, die Weltherrin und ihr Schatten, zu kopieren. - b) und c) über Boltzmann, 1896 Atomistik, zu 
kopieren. - d) Kritisches zu Plank, 8 Vorträge. - e) und f) über Stallo. g) über Buffon. - h) Kraft. - Alles zu kopieren, besonders Auerbach, Boltzmann, Plank und Stallo. -

LXXIV. 1907 Vom Ursprung unserer Überzeugung von der Körperwelt, zu kopieren. -

LXXV. Gegen die Relativisten, sogleich zu kopieren. - 1906

LXXVI. Logisches, a) zur Logik. - b) Anhang zur Abhandlung über den Ursprung mathematischer Erkenntnis, Kritik von Heath, m.p. - c) Broschüre von Land 1875 samt Bemerkungen Antikritik hiezu. - d) Zu Russel, Kopien besitzt Bergmann. - Wollen Gottes, Gottes Wesen. - f) Altes Exzerpt aus Mill. -

LXXVII. Ethisches, a) Ethik und ihre Aufgabe. - b) Strafmotiv und Strafmass. c) Erkenntnis des Guten u Schlechten. - d) Glück und Unglück. - e) Lieben und Hassen. 1907- f) Skizze einer Ethik. - Alles zu kopieren. Rassenverbesserung von Ehrenfels.

LXXVIII. Wissenschaftliche Philosophie gegen Kant, zu kopieren und zu publizieren. - (ex 1905)

LXXIX. Nieder mit den Vorurteilen! Übersetzung, a) Übersetzung der Habilitationsthesen, Kopie liegt bei. wichtig und zu kopieren - b) Gegen die Beschuldigung scholastischer Methode. - e) Vergleich zwischen Brentanos und Wundts Psychologie. - d) Antikritik zur Klassifikation. -

LXXX. $\quad$ a) Gutachten ex 1876 über Lehrbücher der philosophischen Propädeutik für Gymnasien, später abgeändert. wichtig u. zu kopieren. - b) Gutachten ex 1886 über Hebung des philosophischen Unterrichtes an der Universität. -

LXXXI. a) Skizze eines curriculum vitae. - b) Zouboffs Charakter. - c) Brief an Amato ex 1900. - wichtig u. zu kopieren. sehr aktuell!

LXXXII. Pädagogische Vorschläge zu übersetzen für die Reform des Gymnasialunterrichtes, für Italien bearbeitet, zu kopieren, Fragebogen liegt bei. - für Italien besonders wichtig.

LXXXIII. Ausführliche Darstellung und Kritik von Machs Erkenntnis und Irrtum, Nr. 1-10, Nr. 11 und 12 scheint zu fehlen, dürfte aber unter den Manuskripten in Prag sich befinden, wohin sie Brentano einst gesandt hat. - besonders wichtig XXI XXII (nicht eukl. Geometrie u. Geometrie überhaupt.)

Fortsetzung zu Nr. LXXXIII zu Machs Erkenntnis und Irrtum, Nr. 13-25, ferner Aphoristisches zu Mach, Psychognosie Machs, zu Kapitel 2. Weitere Fragen zu Mach. - Zur Würdigung des Positivismus Machs, m.p. aus dem Jahre 1900? zu kopieren. - druckfähig! 
LXXXIV. Nachträge zu Aristoteles. - a) Mannigfache Bedeutung des Seienden, Diktat. - b) Altes Manuskript über Aristoteles über Überschrift Plan. c) 2 Blätter Weltanschauung. -

LXXXV. Nachträge, Diverses. a) Erkenntnis, Hierarchie der Wissenschaften. b) $\mathrm{Zu}$ Aristoteles, Verhältnisbegriffe. - c) ein Blatt Metaphysik, Mai 1901, Aufgabe der Metaphysik. - d) Sinnespsychologisches. - e) Übersicht verschiedenster psychischer Tätigkeiten. - f) ein Blatt über psychische Phänomene. - g) Aus einem Brief an Marty, Cogitans über Zeit. - h) Disjunktives Urteil. - i) Mehrklänge. - Seelensubstanz. - k) Zahl der Sinne. -

LXXXVI. Dilthey Kritik, gezeichnet von Hillebrand, abgedruckt in der Grünhutschen Zeitschrift. -

LXXXVII. Ein Faszikel mit Briefen u. zw. a) ausserordentlich wichtiger Briefwechsel zwischen Fechner und Brentano, beweist u.a. die Priorität Brentanos, betreffend den Einwand eben merklich nicht gleich merklich. - b) Hering, bezieht sich auf Brentanos Experiment hinsichtlich des simultanen Kontrastes. - c) Briefe von Trendelenburg und Hertling ex 1863, letzterer die Abhängigkeit Hertlings. - d) Brief von Wilhelm Scherer. - e) Briefe von Mill und Spencer. - f) Briefe von Husserl. - g) eine Reihe Briefe und Brieffragmente von Brentano, darunter an Arleth, Utitz, Marty, Ehrenfels u.a. Dieser Faszikel wäre genauer zu ordnen und die wichtigsten Briefe bedeutender Männer zu kopieren. -

LXXXVIII. Das Kolleg über praktische Philosophie, das teilweise von Giovanni Brentano kopiert ist und noch weiter zu kopieren wäre, wenngleich die Veröffentlichung im gegenwärtigen Zustande nicht wohl möglich ist. Es bedürfte einer Bearbeitung mit Auswahl der Lesarten bezw. einer endgültigen Redaktion. - Ähnliches gilt von folgender Nr.

LXXXIX. Kolleg über das Dasein Gottes. -

XC. $\quad 2$ kleine Tagebücher aus der Wiener Zeit, die ich Frau Brentano übergeben habe. Es wäre sehr wünschenswert, dass dieselben kopiert würden, da sie für die Persönlichkeit und das ethische Ringen Brentanos überaus charakteristisch sind. -

Poetisches etc.

a. 1. Der standhafte Prinz von Calderon. - 2. Couvert mit Gedichten (F.W.) Original bei Kraus, Prag. 3. Süterling. - Zahlreiche andere Gedichte. -

b. 1. Gedichte, ungeordnet. - 
c. Ein Band Gedichte, eingangs der Stammbuchvers von Justinus Kerner, 208 Seiten. -

d. 1. Faust der Bessere 1879/80. - 2. Gedichte aus der Jugendzeit 1855/60. - 3. Nie betrügt man einen Franzmann. - 4. Metrisches, eigene Versuche, Übersetzungen. 5. Meiner Mutter. -

e. 1. Nie betrügst $\mathrm{Du}$ einen Franzmann. - 2. Der Froschmäusekrieg. - 3. Gedichtenbuch (darunter an Kaiser Wilhelm). - 4. Seufzer ex 1862, Gedichte, Rätsel. - 5. Gedichte. -

f. Schach. -

g. Jugend allerlei. -

\section{IV. [Verzeichnis der im Brentano-Archiv befindlichen Manuskripte, Diktate und Abschriften]}

Mappe No: ${ }^{6}$

Originalmanuskripte. Diktate.

I. Inhaltsangabe der nikomachischen Ethik. I. Mskpt. 1 xBg.

Abschriften.

I. Zur Methode der historischen Forschung auf philosophischem Gebiete. April 1888.

Zur Methode aristotelischer Studien und zur Methode geschichtlicher Forschung auf philosophischem Gebiete überhaupt.

Abschriften.

II. Zur Reform der Mittelschule; Auszug aus einem Fragebogen ital. Zur Mittelschulreform. 1906?

Gutachten über Lehrbücher der Logik und Psychologie für Mittelschulen von Zimmermann, Lindner, Drbal und Beck. Anfang Juni 1876.

Vorschläge zur Belebung des philosophischen Unterrichtes an der Wiener Universität. Brief an den Unterrichtsminister. 1880 (1886).

6 Die römischen Ziffern beziehen sich auf die Nummerierung der Mappen im Prager BrentanoArchiv. 
Abschriften von Marty.

II. Brentanos Vorschläge zur Reform des Mittelschulunterrichtes. 3 Blatt. 1906 und 1904.

Originalmanuskripte. Diktate.

III. Aus dem Manuskript Brentanos zur Psychologie vom empirischen Standpunkte.

$4 \mathrm{xBg}$., $+5 \mathrm{Bg}$.

Abschriften.

IV. Aristoteles über die Zeit. 12. III. 1915.

Kant über die Zeit. 17. III. 1915.

Aristoteles Lehre von der Bewegung. 25. II. 1915.

Stellen des Aristoteles, welche zu berücksichtigen sind in ihrer historischen Ordnung.

4. IV. 1915.

Aristoteles über die Zeit. Aporie. Undatiert.

Aristoteles von der Zeit. 2. IV. 1915.

Aristoteles Physik. 11. III. 1915.

Plotin, Enneaden. Undatiert.

Alte Mythologen. 6. IV. 1915.

Aristotelische Lehre von der Zeit. Für das Verständnis der aristot. Lehre ... 31. III. 1915.

Korrespondenz von Leibniz und Clarke. 17. IV. 1915.

Zur Lehre von Raum und Zeit + einige Blätter aus Franz Brentanos „Zur Lehre von Raum und Zeit“ (Kantstudien). Unvollständige zerfetzte Abschrift. 23. II. 1917.

Mögliche Auffassung der Zeit. 9. V. 1915. [gestrichen]

Abschriften von Marty und Kraus.

IV. Brentano über Urbachs Zeitlehre. 11 Blatt. 1899.

Kraus-Notizen, Plerose. Mit einem Notizbuch teilweise stenographiert. 1900.

Manuskripte und Diktate.

V. Musikalisches Gefallen. 2 xBg. + 1 Karte.

Ästhetik. Mskpt. 2 xBg. Zettel.

Aphorismen über die Musik. Diktat. 5 Str. 5. I. 1916.

Das Weib. Mskpt. 1 xBg. Herbst 1906.

Zur Klassifikation der Künste (Mit einer Einleitung Klassifikation der Sinne).

Diktat. 1905/06.

Das Schöne. Sein Subjekt ist das Vorstellen. Mskpt. 2 xBg. 
Philosophie der Frauen. 2 xBg.

Phantasie. Mskpt. 8 xStr.

Wesen der Lyrik. Diktat. 2 xBg.

Vom Schönen. (Wenn wir ein Mädchen schön nennen). 12 Bg.18./19. XII. 1906.

1 Paket Vorarbeiten zum Vortrag über das Schlechte als Gegenstand künstlerischer Darstellung. Mskpt.

Abschriften.

V. Musikalisches Gefallen.

Aphorismen über die Musik. 5. Jänner 1916.

Das Weib. Herbst 1906.

Das Schöne. (Sein Subjekt ist das Vorstellen.)

Vom Schönen. (Wenn wir ein Mädchen schön nennen). 18./19. Dezember 1906.

Grenze von Poesie und Prosa. Brief Kastil über Gespräch mit Brentano.

Abschrift von Utitz, Kastil.

V. Vom Schönen. (Wenn wir ein Mädchen schön nennen).18./19. Dezember 1906.

Abschriften.

VI. Zu Poincarés erkenntnistheoretischen Aufstellungen. 19. XII. 1916.

Poincaré, Valeur de la science. c.l. Logique et intuition en mathematique.

Zu Poincarés Erkenntnislehre. 1. Dezember 1916.

Zu Poincaré: Jedes mathematische Gesetz, sei es ... 1900?

Manuskripte und Diktate.

VII. Vom Lieben und Hassen. Diktat. 20 xBg. + 1 Bg. 19. Mai 1907.

Abschrift.

VII. Vom Lieben und Hassen. 19. Mai 1907.

Manuskripte und Diktate.

VIII. Klassifikation der Wissenschaften und ähnliches. Disposition. 5 Briefpapiere, 1 Bg., 2 Str. Mskpt.

Abschriften.

VIII. Die Philosophie. 3. Juli 1914.

Einleitung in die Metaphysik. 1879.

Einleitung in die Metaphysik. 1874.

Zur Metaphysik. 16. Dezember 1915. 
Die Gesetze der Wechselwirkung der Naturkräfte und ihre Bedeutung für die Metaphysik. Ein populärer Vortrag. Würzburg.

Ontologische Fragen.

Manuskripte und Diktate.

IX. Das Seiende im Sinne des Wahren. Mskpt. 9 Str.

Vom Denken und vom ens rationis. Diktat. 9 xBg. 18. März 1906.

Zur Frage von der Existenz der Inhalte. Diktat. 11 Str. 20. November 1914.

Gegenstand, Wirklichkeit, Seiendes, Relation. Mskpt. 11 Bg. Vor 1903.

Der Begriff Existierend und sein Aequivokation. Mskpt. 6 xBg.

„Cogitare“. Diktat. Von Brentano (jedenfalls nicht letzte Fassung). 1904?

Vom ens rationis. Diktat. 28 Str. 6. Feber 1917.

Manuskripte. Diktate.

IX. Von den Gegenständen des Denkens. Diktat. 14 Str. 22. Feber 1915.

Über das Sein (Das als Objekt Bestehende hat als solches kein eigentliches Bestehen). Diktat. 8 Str. 30. Jänner 1917.

Abschriften.

IX. Das Seiende. 2. Feber 1914.

Von den Relativen. Palermo. 1899.

Von den sogenannten „Objektiven“. 23. Jänner 1916.

Der Name des Seienden ... 4. Feber 1914.

Wesenhaftes und Unwesenhaftes.

Methode. 18. Sept. 1914.

Aus einem Brief an Prof. Marty.

Brief an Hillebrand. Florenz. 25. Feber 1911.

Zur Frage von der Existenz der Inhalte. 20. Novemb. 1914.

Der Name Existierend und seine Aequivokationen. September 1904.

Zur Lehre von den entia rationis. Diktat. 27. Jänner 1917.

Das Seiende im Sinne des Wahren.

Vom Denken und vom ens rationis. (Aus einem Briefe an Marty.) 1914?

Über die schöne Unterscheidung von Existenz und Sein. 22. Mai 1916.

Von den Objekten. Zum Anhang der Klassifikation.

Das Seiende (für Prof. Marty).

Gegen die Annahme. 28. Jänner 1916.

Ens rationis. Aus einem Briefe an Prof. Marty. Undatiert.

Abschriften von Kraus.

IX. Psychische Tätigkeiten. Florenz. 12. April 1908. 
Über den Begriff des Realen. Florenz. 1. April 1908.

Der Name Existierend und seine Aequivokation. Florenz?

Abschriften.

X. Von der Unsterblichkeit der menschlichen Seele Von der Seele.

Manuskripte. Diktate.

XI. Über Martineaus Types of ethical theory. Diktat. 34 xBg. 12. IV. 1907.

Sittliche Sanktion. Diktat. 3 xBg.

Martineau. Copy aus Martineaus Types of ethical theory Bd. II. Diktat. 2 xBg. Martineau. Diktat. 1 xBg. 7. IV. 1907.

Abschriften.

XI. Martineaus Types of ethical theory. 12. IV. 1907.

Manuskripte. Diktate.

XIII. Entwürfe zu einem Vortrag über das natürliche Recht. Mskpt. 7 xBg., 10 Bg. 1888 ?

Glück und Unglück. Mskpt. 4 Bg. Monogamie. Mskpt. 4 xBg., 1 Str.

Selbstmordartikel (Wiener Tagblatt). Mskpt. 2 Briefpapiere. 2. IX. 1893.

Zur Ethik; Gütertafel. Mskpt. 6 Str. + 6 Bl.

Begriff des komplexen Deliktes, z. B. Ehebruch. Mskpt. 1 Bl.

Vom höchsten praktischen Gut. Mskpt. 6 Str. + 3 Bg.

Worte zum Semesterbeginn. Mskpt. 19 Bl. + 1 Str.

Theismus und Determinismus. Mskpt. 19 Bl. + 1 Str.

Was ist Willensschwäche? Diktat. 2 Str.

Von der Erkenntnis des Guten und Schlechten. Mskpt. 4 Str.

Von der Vollkommenheit eines lebenden Wesens. Mskpt. 15 Str.

Begriff der Philosophie von den menschlichen Dingen. Diktat. 8 Bl.

Disposition zum Ethikkolleg. Mskpt.

Abschriften.

XIII. Indeterminismus und Determinismus. 1914?

Determinismus.

Vom Guten, das in der Zuordnung liegt.

Abschriften von Kraus.

XIII. Der Fehler im Argument des jungen B. Franklin. Mit Abschrift (Maschine). 
Manuskripte und Diktate.

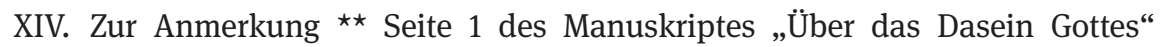
(Ausgeschieden) Diktat. 2 Str.

Abschriften.

XIV. Randbemerkung zu Stumpf: Über den Begriff der mathematischen Wahrscheinlichkeit. (Mit einem Anhang: Stumpfs Gegenbemerkungen.) Abschrift von Stumpf gemacht. 1892.

Randglossen zu Stumpf, kollationiert von Kastil, München. 1892.

Poincaré - Über den Zufall. 2 Exemplare. 22. XI. 1916.

Poincaré - Von der Wahrscheinlichkeit. 2 Exemplare. 17. XI. 1916.

Poincaré - Bemerkungen über die Wahrscheinlichkeitsrechnung in „Wissenschaft und Hypothese“. 2 Exemplare. 22. X. 1916.

Von Poincaré behandelte erkenntnistheoretische Fragen. 16. XII. 1916.

Zum Bertrandschen Paradoxon. Fragment.

Bertrandsches Paradoxon: Brentano an Kastil am 5. III. 1917.

Bertrandsches Problem. Fragment. 2 Exempl.

Brentano an Kastil, 5. März 1917. Anmerkung von Kastil geschrieben.

Zum Bertrandschen Problem über die wahrscheinliche Größe einer Sehne im Verhältnis zur Größe der Seite des einzuschreibenden regelmäßigen Dreieckes. Original vermisst. 2 Exem-plare. 18. I. 1917.

Zum Bertrandschen Problem der Wahrscheinlichkeit, dass eine nicht näher bestimmte Sehne eines Kreises größer oder kleiner sei, als die Seite des einzuschreibenden regelmäßigen Dreieckes. 2 Exemplare. 24. X. 1916.

Zum Bertrandschen Problem: Man denke sich einen Kreis, welcher einen Strahl tangiert ...

2 Exemplare. 22. I. 1917.

Zum Bertrandschen Wahrscheinlichkeits-Problem. 2 Exemplare. 7. I. 1917.

Zum Bertrandschen Sehnen-Problem. 2 Exemplare. 24. I. 1917.

Ich muss offenbar die Sehnen gleich dicht aneinanderlegen ... Fragment? 3 Exemplare. Undatiert. [gestrichen]

Zu Bertrand, Calcul des probabilités, Er finde es paradox, dass es Gesetze des Zufalles geben soll ... 2 Exemplare. 5./6. XI. 1916.

Gegen die Behauptung der Willkür der ersten Annahmen bei der Bestimmung einer Wahrscheinlichkeit. 3 Exemplare. August 1906.

Von dem empirischen Element in unserer Algebra und der Frage ob und inwiefern dasselbe ihre Allgemeingiltigkeit beschränke. Undatiert.

Laplace. Einleitung zu den kritischen Besprechungen 84/85. 
Abschriften von Marty.

XIV. Das Urteil über Wahrscheinlichkeit. Fragment. Mspt. \& Abschrift. Notizen von Marty zu Brentano. Wie man apriori zeigen könnte, dass ein grundloses Werden absurd, so würde dies ... 2 Blätter undatiert, + 1 Blatt datiert. 7. XII. 1911.

Manuskripte und Diktate.

XV. Anschauung und abstrakte Vorstellung, anschaulich einheitlich und attributiv einheitliche Vorstellung. Diktat. 7 Str. 9. III. 1917.

Zur Lehre von der inneren Wahrnehmung. Diktat. 4 Str. 1. IV. 1915.

Zur Lehre von den Universalien. Fragt man, ob unser Denken sich jemals auf ... Diktat.

10 Str.

Abschriften.

XV. Vorstellen und Urteil. 22. Mai 1906.

Die Verneinung. Eine Verneinung kann nicht eine Anerkennung enthalten, sonst wäre jede ... Undatiert.

Vorstellen und Begriff. Beide Ausdrücke werden in mannigfachem Sinne gebraucht ... Undatiert.

Glauben und Leugnen kein Werten. - Vorstellen von Urteilsinhalten. - Das Annehmen weder bloßes Vorstellen noch Urteilen, aber wie diese affirmativ oder negativ. Alles auf 1 Blatt. Undatiert.

Kein negatives Vorstellen. Man sagt nicht bloß ... Undatiert.

Gegen die Annahme als besondere Grundklasse psychischer Beziehungen. 28. I. 1916.

Überlegenheit unseres psychologischen Wissens. „Unser psychologisches Wissen ist unserem physiologischen ..." Undatiert.

Vom Objekte. Feber 1906.

Von dem zu etwas sich Verhaltendem. 8. I. 1915.

Phantasie. Was bedeutet der Name? Was nennt man Phantasien ... Original in Mappe V. Undatiert.

Von der Natur des Vorstellens. Dupl. 1903 (?).

Manuskripte und Diktate.

XVI. Autobiographische Notizen. 2 Str. 3 Bl. Diktat.

Ein Zeitungsartikel über Clemens Brentanos Briefe an Sophie Mereau.

Abschriften.

XVI. Biographische Notizen von Franz Brentano. 2 Exempl. 
Meine philosophischen Studien machte ich an verschiedenen deutschen Universitäten ...

3 Exempl. Undatiert.

Franz Brentano. Meine Knabenjahre verbrachte ich in Aschaffenburg ... 3

Exempl.

Brentano an seine Mutter.

Unter meinen Lehrern haben ... Undatiert.

Von Lehrern haben E. v. Lasaulx ... Undatiert.

Manuskripte und Diktate.

XVII. Über Kants Kritik der Gottesbeweise. Diktat. 3 xBg.

Schopenhauer. Diktat. 3 xBg.

Abschrift der Bemerkungen über die Theodizee von Leibniz. Diktat. 4 Bg.

Abschriften.

XVII. Was an Reid zu loben und zu tadeln. 3. IX. 1916.

Thomas Reid. 17. VI. 1916.

Über Royer-Collards von Jouffroy mit der Übersetzung von Reid veröffentlichte Fragmente. Anfang August 1916.

Reid. Seine historische Stellung ... 14. VIII. 1916.

Zu Reid. Wir finden ihn als energischen ... Juli 1916.

Thomas von Aquino, einige Seiten.

Leibniz' Beweise des Daseins Gottes im Anfang des 2. Buches (No 7) der Theodizee.

28. IV. 1914.

Leibniz' Theodizee. Bemerkenswert ist, dass Leibniz das wesentliche Verdienst der christlichen Offenbarung ... 29. VIII. 1908.

Aus den Briefen von Leibniz an de Bosses (fehlt eine Zeile). 14. IV. 1915.

Leibniz. Monadologie. Unter einfacher Substanz ist nicht eine solche gemeint, die keine Zusammensetzung ... Undatiert.

Nietzsche ist ein missratener Philologe und ein philosophischer Dilettant, der nur bei Lehrern der Verfallszeit ... 3. XI. 1915.

Zu Leibniz Lehre von Raum und Zeit. 27. III. 1915.

Pascal. Eine wunderbare Vereinigung von wissenschaftlichem und künstlerischem Talent und heiligem Edelsinn. Undatiert.

Pensées sur les miracles (Pascal). Wunder als Anhalt ... Undatiert.

Renan. Souvenir d'enfance. P. 180 - 182. Undatiert.

Clarke. Über das Dasein und die Attribute Gottes. [H 2]

Kant. Über die Religion innerhalb der Grenzen der bloßen Vernunft. Was

Kant sich über Religion denkt ... Undatiert. 
Kritisches zu Leibniz’ Optimismus. 17. IV. 1915.

Zu Bäumkers äußerem und innerem Sinnesvermögen. Oktober 1909.

Kant: Ontologischer, kosmologischer und teleologischer Beweis. Zürich. 1915 oder 1916.

Exzerpt aus Augustinus. I. Buch S. 10. Lust und Leid sind ... Undatiert. Abschrift der Bemerkung über die Theodicee von Leibniz. Undatiert.

Abschriften.

XVIII. Moderne Irrtümer über die Erkenntnis der Gesetze des Schließens. Philosophische Gesellschaft 1890/91.

Manuskripte

XIX. Hausaufgaben aus der Philosophie für Lehramtskandidaten. Juli 1895.

Zwei Entwürfe eines Briefes an einen Professor, der eine Abhandlung über Sophismen und Paralogismen zugeschickt hat.

Abschriften.

XIX. Zu Russell. Über die von sich prädikablen und nicht prädikablen Klassen. 2 Exemplare. 1909.

$\mathrm{Zu}$ Russell. Über die von sich prädikablen und nicht prädikablen Klassen. II. Russell gibt dem Paradoxon folgende Fassung. 1909.

Russells Paradoxon (III). Seine Lösung. Undatiert.

Russells Paradoxon (IV). Mit Beilage. Seine Lösung. Undatiert.

Russells Paradoxon. (Scheint an Bergmann gerichtet.) Undatiert.

Brieffragment an Dr. Bergmann, betreffend Russells Paradoxon. Florenz. Feber 1909.

Leibniz-Russell. Correspondence de Leibniz et d'Arnauld. 2 Exempl. 26. Jänner 1915.

Manuskripte und Diktate.

XIX. Russell gibt dem Paradoxon folgende Fassung (scheint an Bergmann gerichtet).

3 xBg. Diktat. 20. II. 1909 (?).

Brief von Brentano an Dr. Bergmann. Florenz. Diktat. 1 (2xBg). 21. II. 1909.

Abschriften von Marty und Dr. Bergmann.

XIX. Brentano über das Russell'sche Paradoxon, an Dr. Bergmann. Abschrift von Marty. 21. II. 1909.

Bergmann an Brentano. Antwort auf den Brief vom 21. II. 1909. 
Abschriften.

XX. Vom Vertrauen auf das Gedächtnis. Hume, der so skeptische, hat unser Vertrauen auf das Gedächtnis ...

Gedächtnis. Seite 1-9. 24. IV. 1913.

Gedächtnis. Seite 10-15. 23. IV. 1913.

Psychische Tätigkeiten. Florenz. 12. IV. 1908.

Perzipieren, apperzipieren, deutlich apperzipieren. Wo etwas vorgestellt wird, wird apperzipiert ...

Abschriften.

XXI. Brentano gegen Mach. Blatt 1 fehlt. Darnach darf es uns eben nicht sehr befremden, wenn Mach auch innerhalb ...

Manuskripte und Diktate.

XXII. Gegen die Relativisten. Diktat. 17 Bg. Feber 1906.

Abschriften.

XXII. Zu Bechers Weltgebäude. Der Verfasser ist belesen und ... Anmerkung von Kraus: Diesen Artikel hat er Kastil zu Beginn 1914 gesendet. Vor 1914 habe ich ihn nicht gesehen. 1915 (?).

Gegen die Relativisten, von Fr. Brentano. 1906.

Gegen die Relativisten. Lose Blätter. Undatiert.

Die Einsteinsche Relativitätslehre. 2 Exemplare. 29. X. 1914.

Zur Lorenz-Einsteinfrage. 30. I. 1915.

$\mathrm{Zu}$ Lorenz Erfahrungsversuch [sic!] der von Michelson gemachten Erfahrungen. 2 Exem-plare. 10. III. 1915.

Abschriften.

XXIII. Der Atheismus und die Wissenschaft. Dies ist der Titel eines Aufsatzes, der vor etlichen Wochen im ...

Der Beweis aus der Bewegung. Dieser Beweis steht zu den zuvor betrachteten Argumenten in einem eigentümlichen Gegensatze ...

Brief an Faggi bezüglich seiner Schrift gegen den Optimismus. Palermo. 23. III. 1899.

Inhaltsverzeichnis. Über den Optimismus. Brief an Faggi. 25. III. 1899.

Aristoteles, wo er zu früheren Ansichten Stellung nimmt. 21. IV. 1908.

Dasein Gottes. Abgekürzte Darstellung des Beweises vom primus motor und Fragment einer solchen des teleologischen Beweises.

Über das Prinzip des hinreichenden Grundes. 10. I. 1917. 
Optimismus und Pessimismus. Wie bei der Beantwortung einer Frage nur eine Antwort richtig, alle anderen unrichtig sind ...

Das Gesetz des ausgeschlossenen Zufalls. Ein Fall des Gesetzes der Kontradiktion.

15. V. 1914.

Zum Kontingenzbeweis. Kontingenz im eigentlichen Sinne nennt man das, was weder notwendig ...

Zum Gottesbeweis. 10. IV. 1914.

Disposition. Von dem Nachweis der Existenz eines unmittelbar notwendigen Wesens und seiner Beziehung zum Gottesbeweis.

Vom Schlechten und seiner Vereinbarkeit mit der Allgüte Gottes. Gott, unser „Vater“. Die Christen nennen Gott unsern Vater ...

Zum Gottesbeweis. (Später abgeändert.) 10. IV. 1914.

Ordnung des Gottesbeweises. Jänner 1914.

Zum Kontingenzbeweis. Die Körper sind endlich an der Zahl, wie an Größe ...

Gott und Welt. Unter allen Wesen ist eines, das ursachlos in sich selbst notwendig ist ...

Vom Schlechten. Dass es relativ schlechte Dinge gebe, wagt niemand zu leugnen.

Dagegen ...

Von der Seligkeit Gottes und ob die ewige Freude, deren er geniesst, eine intensive sei?

Einheit der notwendigen Substanz. 6. V. 1914.

Von dem Nachweis der Existenz eines unmittelbar notwendigen Wesens und seiner Beziehung zum Gottesbeweis. I. Erläuterung des Begriffes.

Von der Existenz eines unmittelbar notwendigen Wesens. Brief an Prof. Marty, Antwort auf dessen Brief. 7. X. 1912.

Von dem Nachweis der Existenz eines unmittelbar notwendigen Wesens. Brief von Prof. Marty vom 28. IX. 1912.

Es kann nichts absolut Zufälliges geben, vielmehr ist alles, was ist, dann wann es ist, notwendig. 6. VII. 1915.

Von der Unmöglichkeit absoluten Zufalles. 18. III. 1914.

Die Unmöglichkeit eines schlechthin Tatsächlichen. 3. I. 1914.

Gedankengang beim Beweise für das Dasein Gottes. 2 Exempl. 24. VI. 1915.

Abschriften von Kraus und Marty.

XXIII. Brentaniana. Dasein Gottes. Marty-Notizen.

Der Gottesbeweis vom unbewegten Beweger. Marty-Notizen. 1915. 
Vom Nachweis eines unmittelbar notwendigen Wesens und seiner Beziehung zum Gottesbeweis. Von Marty.

Zur Theologie und Teleologie. Von Marty. 15. Juli 1918.

Vom Schlechten und seiner Vereinbarkeit mit der Allgüte Gottes. KrausNotizen. Undatiert.

Von der Notwendigkeit einer ersten Ursache und ihrer Unersetzlichkeit durch eine anfangslose Kette sekundärer Ursachen. Duplikat. Abschrift von? Undatiert.

Gedankengang beim Beweis für das Dasein Gottes. Abschrift nicht bekannt von wem.

5. I. 1917.

Gedankengang beim Beweis für das Dasein Gottes. Abschrift nicht bekannt von wem.

2. I. 1917.

Gedankengang beim Beweis für das Dasein Gottes. Abschrift nicht bekannt von wem.

1. I. 1917.

Manuskripte. Diktate.

XXIV. Drei Abhandlungen Brentanos zu Theophrast. a) b) c)

Diktate.

1 Paket Vorarbeiten zum Theophrast, von Prof. Kraus.

Abschriften.

XXV. David Hume. The natural history of religion. Einleitung. Wichtigkeit zu zeigen, wie die Religion in der Vernunft ...

Hume. Gespräche über natürliche Religion. Von den Überzeugungen auf dem Gebiete der Theologie ...

Hume. Über partikuläre Providenz und jenseitiges Leben. Interessant ist, dass gelegentlich Philosophie ...

Bemerkungen zu Humes Gesprächen über die natürliche Religion. 2. IV. 1914.

Abschriften.

XXVI. Krausaufzeichnungen aus Brentanos Leben, mit Abschrift.

Abschriften.

XXVII. Zur Parallelentheorie. Aristoteles Phys. II, 9, sagt, dass aus der Definition der geraden Linie der Lehrsatz folge, ... Jahr 1909. 
Zum Parallelenproblem als Ergänzung der Beweisfrage von Legendre. 1. Es ist erwiesen, dass, wenn der Satz, den Euklid als II. [?] ...

Parallelentheorie. Lehrsätze und Beweise.

Abschriften von Marty. Kraus.

XXVII. Parallelenaxiom, Abschrift von Marty. Wenn in einer Ebene zwei Gerade ...

Beweis, dass die gerade Linie die kürzeste zwischen zwei Punkten ... Abschrift von Marty.

Beweis, dass die Gerade die kürzeste Linie zwischen zwei Punkten ... Abschrift von Kraus.

XXVIII. Zur Kategorienlehre: Wie andere wissenschaftliche Termini, so hat auch ... 6 xBg. Diktat. (letzte Ausführung).

Vom Selbstbewusstsein, vom Ich, von der Substanz und ihrer Scheidung in geistige Substanz, körperliche Substanz und Wesen von beliebiger anderer Zahl der Dimensionen. Diktat. 8 xBg.

Kategorienlehre. Mskpt. 1 xBg. +1 Bl.

Kategorienlehre. 2 Str. Mskpt.

Abschriften.

XXVIII. Weisheitslehre. Original ohne Titel. Von Prof. Kraus obiger Titel. 2. III. 1916.

Dieses am 2. III. 1916 begonnene Diktat trägt keine Überschrift, doch konnte ...

Inhalt. 1. Nennen als Teil der Rede. Verständlichmachen ...

Vom Selbstbewusstsein, vom Ich, von der Substanz und ihrer Scheidung in geistige, körperliche Substanz und Wesen von beliebig anderer Zahl von Dimensionen. 2 Exemplare. (Nicht aus dem letzten Lebensjahr.)

Kategorienlehre. 30. Sept. 1914.

Vom Begriffe der Substanz, gegen Wundt und Mill. Undatiert.

Substanz. 1. V. 1913.

Philosophische Meinungen über die Substanz. 14. IV. 1912.

Alte Substanzlehre. Das, was ist, wird und endet ... Palermo. 1899?

Wesen, Substanz, Subjekt, Suppositum, Essenz. 15./16. V. 1908.

Von der Substanz. Inhalt: es gibt nicht reale Bestimmungen.

Von der Substanz. I. Kap. Einleitung, II. Kap.Vom Seienden. Hier auch die Lehre von ...

Abstraktion. Einen Gegenstand nennen wir jegliches, worauf eine psychische Tätigkeit ... Palermo. 1899.

... sein wird. Auch dann ist die Grenze, nach ... 1. Seite fehlt. 24. VI. 1914. 
Abschriften von Kraus und Marty.

XXVIII. Älteres, wohl von B. Man muss unterscheiden zwischen psych. Substanz ... Von Marty.

Zur Kategorienlehre. Von Kraus. 1913.

Kategorienlehre. Abschrift genommen in Schönbühel (Kraus). September 1903.

Manuskripte und Diktate.

XXIX. Infallibilitätsschrift. Mskpt. 15 xBg. + 5 Beilagen.

Notizen zur Infallibilitätsschrift, bestehend aus 4 Bl. Mskpt.

Abschriften von Kraus, L. Brentano.

XXVIII. Weisheitslehre. Original ohne Titel. Von Prof. Kraus obiger Titel. 2. III. 1916.

Aufzeichnungen aus Cecconi’s Werk von L. Brentano mit Brief. 28. April 1930.

Kraus-Notizen, 2 Blätter. Oktober 1869?

Abschrift eines Briefes von Dr. Hefele an ? Rottenburg. 10. August 1870.

Abschriften.

XXIX. Über die Infallibilität des Papstes. 23. Feber 1908.

Entwurf zur Denkschrift der deutschen Bischöfe gegen die Unfehlbarkeit aus 1869 vide Kraus, Brentano Seite 8. Dabei ein Brief von Hefele aus 1870. 3 Exemplare.

2 Abschriften des Briefes von Hefele. Rottenburg. 10. August 1870.

XXX. Unrichtige, irrige Vorstellungen, wo die Anerkennung ... Mskpt. 1 Bl. [nicht mehr aufgelistet]

Abschriften.

XXX. Von der Zahl und dem analytischen Charakter der algebraischen Wahrheit. Es gibt unbestimmte Begriffe. Unter sie kann ...

Zahlen. Eine Zahl ist 1, 2, 3, 4, so wie jede andere Mengengrösse, welche durch Zählung messbar ist ...

Der Begriff Zahl. Man müht sich, den Begriff „Zahl“ zu definieren. Indem man so angestrengt sich abarbeitet ... Vor 1908, 1906?

Unendliches von der Zahl. Über ein Axiom von Archimedes. Um zu zeigen, dass die unendliche Zahlenreihe ...

Zur Grössenlehre: Aristoteles lehrt, der Gedanke des Einen ... 24. November 1913. Von der Grösse: Es gibt Gattungen, deren Species ... 1904 oder früher.Benannte und unbenannte Zahlen. 20. Juni 1901. 
Von dem empirischen Element in unserer Algebra und der Frage ob und inwiefern dasselbe ihre Allgemeingiltigkeit beschränke.

Zur Mächtigkeitslehre: In der Mächtigkeitslehre muss man, um den sichtlichsten Absurditäten zu entgehen ...

Die Aufgabe der Megethologie: Unter Megethologie verstehe ich den Inbegriff jener Wahrheiten ...

Skeptische Angriffe auf die Megethologie. Gegen die diskrete Grösse.

Zur Lehre vom Unendlichen. 11. XII. 1913.

Lieber Freund! Gestern erhielt ich Ihren lieben Brief mit Einlage. Indem ich Ihnen dafür danke ... Abschrift eines Briefes von ? an ? Undatiert.

Abschriften von Marty, Kraus etc.

XXX. Von dem empirischen Element in unserer Algebra und der Frage ob und inwiefern dasselbe ihre Allgemeingiltigkeit beschränke. Abschrift von Marty.

Über den Ursprung der mathem. Erkenntnis. Absch. Kraus.

Über den Ursprung der mathematischen Erkenntnis. Marty. 1900.

Abhandlung über Continuum, mathematische Fragen. Beginnend mit § 40, aber von Seite 1. Beweis, dass die Punktmenge einer Geraden gleichmächtig der Punktmenge eines Quadrates. Abschrift von Marty.

Von der Zahl und dem analytischen Charakter der algebraischen Wahrheiten. Es gibt unbestimmte Begriffe. Unter sie kann solches fallen ... MartyAbschrift.

Vom Unendlichen. Die Mathematik in der Lehre von ihren Prinzipien enthält ... Unbekannt von wem die Abschrift.

Mappe No XXXI leer.

Manuskripte

Einleitung in die Metaphysik. 1874.

[Manuskripte und Diktate]

XXXII. Metaphysik. Einleitung. Mskpt. 20 Bl. 17. X. 1877.

Vorlesungen über Metaphysik. Mskpt.

Zur Metaphysik (alte Vorlesungen). Mskpt. Ungeordnete Blätter.

Metaphysik. Einleitung. Begriff der Metaphysik ... Mskpt. 1 xBg.

Kosmologie. Mskpt. 9 Bl.

Aporien zur Metaphysik. Mskpt. 3 Bg. 1868.

Metaphysik. Diktat. 33 Str. 16. XI. 1915.

Was ist Philosophie? Mskpt. 2 xBg. 
Abschriften.

XXXII. Axiome. 21. IX. 1914.

Zur Axiomatik. 13. I. 1916.

Die Erkenntnistheorie. Florenz. 4. IV. 1908.

Abhandlung über die Axiomenlehre. 16. II. 1916.

Metaphysik. Einleitung. 17. X. 1877.

Metaphysik. Einleitung. 15. VI. 1914.

Weisheit. 13. VI. 1915.

Die Weisheit. Von der Erkenntnis. Definitionen. Axiome. Ontologische Lehrsätze. Theologisches, kosmologische Lehrsätze. 30. VIII. 1914.

Einteilung der Metaphysik. Ihr Verhältnis zu anderen Wissenschaften. 4. August 14.

Der Lehrer kann nicht lehren ohne von dem, den er belehrt ... 28. I. 1913. Metaphysik. I. Teil. Florenz. 1908.

Die Weisheit. Dass uns die Weisheit nicht von Natur ... 2 Exempl. 15. VI. 1916.

Die Weisheit, ihr wissenschaftlicher Charakter, ihr Gegenstand und ihre Aufgabe im einzelnen. 12. V. 1916.

Von den Segnungen, die von altersher der Weisheit nachgerühmt werden. 25. IX. 1913.

Aristoteles' Metaphysik. Die Weisheit im Unterschied von anderen Erkenntnissen. Vierfacher Sinn des Namens Ursache, Materie ...

Zur Metaphysik. 16. XII. 1915.

Zur Metaphysik. Florenz. 1. IV. 1908.

Metaphysik - Skizze. Erkenntnistheorie - Ontologie - Existenz Gottes Vom Wesen Gottes - Vom Kosmos. 21.-23. VII. 07, 5. III. 08.

Metaphysik. 8. IV. 1908.

Ontologie. Ontologische Fragen. 2 Abschriften. 25.-30. IX. 1908.

Zur Einführung in die Metaphysik. 23. V. 1916.

Definition der Metaphysik in 3 Exemplaren. 24. III. 1908.

Einleitung der Philosophie. Disposition. 1908.

Übersicht über die Probleme der Metaphysik. Undatiert.

Kosmologische Thesen. 1908?

Nichts ist anzuerkennen, was nicht vorzustellen ist. Alles, was vorgestellt wird, wird mit ... Undatiert.

Abschrift von Kraus.

XXXII. Metaphysik. Definitionen. Abschrift von Kraus. 24. III. 08. 
Manuskripte und Diktate.

XXXIII. Gedankengang zur Lehre von der Evidenz. 3 Str. 8. III. 1915.

Über den Sinn des Satzes veritas est adaequatio rei et intellectus. 6 Str. Diktat. 11. V. 1915.

Über den Satz: veritas est adaequatio rei et intellectus. 3 Str. Diktat. 5. III. 1915.

Man sagt meist: das ist evident, nicht: das ist mir evident. Wohl darum ... Diktat.

2 Str. 12. VII. 1915.

Alle evidenten Urteile sind entweder unmittelbar oder mittelbar evident ... 2 Str. Diktat. 12. VII. 1915.

Über den Begriff der Wahrheit. 1889.

Abschriften.

XXXIII. Über den Sinn des Satzes: veritas est adaequatio rei et intellectus. 11. V. 1915.

Über den Satz: veritas est adaequatio rei et intellectus. 5. III. 1915.

Über den Sinn und die wissenschaftliche Bedeutung des Satzes veritas est adaequatio rei et intellectus. 12. V. 1915.

Erkenntnistheorie. Fragment. Bedeutung der Erkenntnistheorie. $\mathrm{Zu}$ den Theorien, welche von ...

Zur Erkenntnistheorie. Nach Aristoteles besteht ein absoluter Zufall nicht, alles ist, vielmehr ...

Von der Erkenntnis. Duplikat. 1899? 1903?

Über den Begriff der Wahrheit. Nicht vollständig. Da Aristoteles die Wissenschaft im weitesten ...

Aus einem Briefe von Brentano an Marty. Sie verstehen unter „ens rationis“ das Nichtreale ... Undatiert.

Einige lose Blätter aus einem älteren Metaphysik-Kolleg von Brentano. 1 lithographierte Abschrift: Über den Begriff der Wahrheit. 27. III. 1889.

Abschriften.

XXXIV. Gegen den Anschluss Deutsch-Österreichs ans deutsche Reich: Unterschiedliche Begriffe, die mit dem Wort Nation ...

Franz Brentano an Herbert Spencer. Oktober 1872.

[Manuskripte und Diktate.]

XXXV. Prinzip der Systematisierung der Wissenschaften. Mskpt. 1 Bl.

Natürliche Klassifikation unserer Erkenntnisse. Mskpt. 1 Bl.

„Gesamtheit der Wahrheit nach dem ...“ Mskpt. 3 Bl. 
Übersicht über die uns möglichen Wissenschaften. Mskpt. 2 xBg. Entwurf zur Klassifikation der Wissenschaften. Mskpt.

Abschriften.

XXXV. Wissenschaft. I. Begriff der Wissenschaft. 29. XI. 1907.

Begriff und Klassifikation der Wissenschaft. Übersicht des Aufsatzes vom 26. I. 1906. 28. XI. 1907.

Begriff und Klassifikation der Wissenschaften. Was ist Wissenschaft? Die gangbaren Bestimmungen des Begriffes ... 26. I. 1907 (06)?

Abschriften.

XXXVI. Begriff: Die Verwirrung, welche heute die Philosophen am gemeinsamen Fortbau der Wissenschaft hindert ... Mai 1906.

Worterklärungen. Ding ist ein Name, welcher so allgemein ... 7. II. 1914. Erklärung: Unter einem Denkenden verstehen wir etwas, was sich auf etwas in was immer für einer Weise als ... 11. VI. 1915.

Von der Definition: Unter Definition versteht man die Erklärung eines Namens. Der aber erklärt einen Namen ...

Von den Definitionen: Einleitung. Doppelte Aufgaben, Klärung sprachlicher Ausdrücke und Verdeutlichung ... 20. IX. 1914.

Ein Ausdruck kann uns vollkommen geläufig und doch zugleich sehr wenig deutlich sein. Der Name Hund ist dafür ...

Apodiktizität: Unsere evidenten Urteile sind zum Teil rein assertorisch, wie z.B. die Selbstwahrnehmung ...

Von den transcendenten Begriffen und Erkenntnissen. Die Erkenntnis ist ein Urteil. Eine andere Vorbedingung ...

Abschriften von Kraus.

XXXVI. Von der Definition. Unter Definition versteht man die ...

Der Grund warum man nicht darauf verfällt ... (wichtig). Zeit vor Brentano?

Manuskripte und Diktate.

XXXVII. Leib- und Seeleproblem. Verbindung von Leib und Seele. Mskpt. 3 Bl. Feber 1891.

Abschriften.

XXXVII. Die Seelensubstanz in der inneren Anschauung gegeben. Kein Akzidens denkbar ohne Einschluss der ... 1914? 
Von der Seele: Der Ausdruck „Seele“ wird von Verschiedenen in verschiedenem Sinne gebraucht ...

Puntini. 21. IV. 1913.

Nachtrag zu den Puntini. Man berichtet mir von Beobachtungen, die man bei Sterbenden gemacht haben will ...

Puntini. Wir sagen, dass etwas sei; wir sagen auch ... 18. IV. $1913 \mathrm{zu}$ Blatt I.

Puntini III. Von der Geistigkeit der Seele. Während die äußere Wahrnehmung uns Räumliches und räumlich ...

Nachtrag II. zu den Puntini. Florenz. 29. III. 1908.

Zur Würdigung der „Puntini del corso obligatore d'Anatomia Comparata per gli studenti di I anno“. 1900.

Zum Beweis der Geistigkeit der Seele. 1913-1915.

Puntini: Die Puntini identifizieren Leib und Seele ... Florenz. März 1913. Puntini. Unterscheidung von Erkenntnis seiner selbst ... 16. IV. 1913.

Puntini: Stellung der Aufgabe. Untersuchung der Frage. 18. IV. 1913.

Puntini: Einleitung. Standpunkt der Puntini.

Ontologischer Teil. Puntini. Verhältnis der Kontinuität im allgemeinen. 12. IV. 1913.

Von der Unsterblichkeit der menschlichen Seele. (Übersicht.) 31. I., 8. II. 1916.

Puntini. Ältere Fassung III. Florenz. 13. III. 1913.

Puntini. Ontologischer Teil. 11. IV. 1013.

Puntini. 18. IV. 1913.

Abschriften von Marty, Kraus.

XXXVII. Zur Würdigung der Puntini. Abschrift von Marty. 1908.

Falsche Voraussetzung, dass Denken ... 2 Blatt von Marty. 29. Juli ?

Notizen von Kraus. Stenographiert.

Abschriften.

XXXVIII. Von der Tierseele und dem eventuellen psychischen Leben der Materie. Über das Seelenleben der Tiere. Aus einem Briefe an Utitz: Was die menschlichen Seelen anlangt, so kann ...

Romanes, geistige Entwicklung im Tierreich. Das Kriterium des Geistes. R. sagt mit Recht, für uns sei ...

Brief Brentano an Dr. Utitz. Duplikat. Schönbühel. 14. Okt. 1906.

Abschriften.

XXXIX. Aphorismen. 17. II. 1917. 
Antikritik einer Rezension der „Klassifikation etc.“: Der Kritiker hat sich mit Liebe in die Abhandlung ...

Vergleich zwischen Brentanos und Wundts Psychologie: Es sind jetzt 30 Jahre, seit mein erster Band ...

Gegen den Vorwurf scholastischer Methode: Vor längeren Jahren schon wurde mir erzählt, in Berlin ...

Manuskript.

XL. Zu § 63 B.G. Ehehindernis der höheren Weihen. Mskpt: 2 Brouillons Krasnopolskis letzter Versuch und 1 Brouillon Meine letzten Wünsche für Österreich.

Abschriften.

XL. Krasnopolskis letzter Versuch über das Ehehindernis wegen Weihe oder Gelübde.

Brentano gegen Krasnopolski ein Teil. (Das Persönliche noch ungedruckt.)

Abschriften.

XLI. Ursache: Kausalgesetz und Induktionsbeweis dafür.

Ist es die Aufgabe nur einer oder mehrerer Wissenschaften, die Ursache darzutun, ob die ...

Von der wirkenden Ursache. 16. I. 1914.

Von der wirkenden Ursache. 19. I. 1914.

Ursache: Man hat die Forschung nach den Ursachen in acht und aber acht erklärt ...

Abschriften von Marty.

XLI. Convenienzwissenschaftslehre. Von Marty. 26. VII. ?

Ursache. Abschrift von Marty. 17. VII. 1910.

Ursache, Gott. Abschrift von Marty. 25. VII. 1906?

Manuskripte und Diktate.

XLII. Verschiedene nicht identifizierte Fragmente, die beim Unsterblichkeitskolleg lagen. Mskpt.

Teile eines früheren Kollegs über die Unsterblichkeit der Seele. Mskpt.

Gespräche mit Müller und Grossmann über das Dasein Gottes und die Unsterblichkeit der Seele. Mskpt. In einem braunen Umschlag.

Unsterblichkeitskolleg. Mskpt. 157 S. und Beilagen. 1875/76.

Älteres über Psychophysik. Mskpt. 6 Bl. 5. II. ? 
Abschriften von Marty.

XLII. Unsterblichkeit. Woher kommt die Seele?

Über die Unsterblichkeit: Objektion von Ehrenfels mit d. Laplace'schen Geist ...

Einige Blätter über die Seele, von Marty. Entsteht durch die trans. Zeit ... Immaterialität und Unsterblichkeit. 1899.

Über Unsterblichkeit und Dasein Gottes. Zusammenhang mit der Frage nach dem höchsten praktischen Gut. Einzige Hoffnung ...

Marty-Aufzeichnungen betreffend Brentano Geistigkeit der Seele. Wichtig! 1913.

Abschriften.

XLIII. Die Frage nach der Möglichkeit transzendenter Erkenntnisse. Der einfachste Beweis und ...

Abschrift eines Briefes an Dr. Hennemann, über die Notwendigkeit Gottes. 3. V. 1912.

Gegen die vermeinte Evidenz der äusseren Wahrnehmung. 4. XII. 1907.

Von den sogenannten Objektiven. 23. I. 1916.

Entia rationis. 2 Exemplare. 5. II. 1917.

Wer denkt, denkt etwas. Dies „Etwas“ ist eindeutig; sonst würde auch der Terminus „denken“ ... Schönbühel. 31. V. 1914.

Über die schöne Unterscheidung von Existenz und Sein. 22. V. 1916.

Ein Ausdruck kann uns vollkommen geläufig und doch zugleich sehr wenig deutlich sein ...

Das Seiende. Seiend nenne ich etwas, was ist, insofern es ist ... (für Prof. Marty).

Nieder mit den Vorurteilen! Ein Mahnruf an die Gegenwart im Geiste von Bacon und Descartes, von allem blinden Apriori sich loszusagen.

Das Problem der Induktion. Nach einer Abschrift Dr. Eisenmeiers. Schönbühl. 1906.

Der Solipsismus und seine einzige stichhaltige Widerlegung. 18. III. 1915. Vom Ursprung unserer Überzeugung von der Körperwelt. 4. IV. 1907.

Abschriften.

XLIV. Bemerkungen zu Stallo. S. 16 wird zugegeben, dass der Beginn mechanischer Erklärungsversuche in der Geschichte der Wissenschaft epochemachend ... 
Abschriften von Kraus.

XLIV. Bemerkungen Franz Brentanos zu Stallo. Stenographierte Notizen, die abgeschrieben (vide Florentiner Notizen).

Manuskripte und Diktate.

XLV. Über die Lehre Jesu und ihre bleibende Bedeutung. Diktat. 74 Str. 16., 20., 23., 24. VIII. 1915, 2. IX. 1915, 14. II. 1916.

Jesus und Christentum. Mskpt. 4 xBg. + 1 Bl.

Ich habe in letzter Zeit fast nur Theologica geschrieben ... Mskpt. 5 S.

Über „Hibbert Lectures“ v. P. le Page Renouf. Diktat. 8 S. Florenz. 29. IV. 1904.

Religionsphilosophisches. Fragment. Die Religion ist die Philosophie des Volkes. Mskpt.

$2 \mathrm{xBg}$.

Kritische Bemerkungen zu Schell „Die Welt und Gott“. 20 Seiten abgeschrieben. In einem Kuvert. Diktat. 1 Bl. Datiert mit Schönbühel 28. XI. 11.

Abschriften.

XLV. Newman. Frage ob unmittelbare Eingriffe oder uranfängliche providentielle Ordnung. Leibniz ...

Begriffe der Religion. Religionsphilosophie. 29. VI. 1912.

Religionsphilosophische Skizze. Was ist Religion? 1911.

Philosophischer Versuch über die Religion. I. Buch: Die Weisheit und ihre Surrogate ...

27. IX. 1912.

Zur Religionsphilosophie. Wir hörten unter anderem ... 3. IV. 1914.

Philosophische Untersuchungen über die Religion: Die Lehre von einer unendlichen vollkommenen, alles beherrschenden ...

Vaticanum - die dogmatische Konstitution über den kath. Glauben. Fragment.

Entwurf über Religion. Anfang fehlt. - Wohl zum Forschen ...

Die Religion: Die Religion ist die Philosophie des Volkes, oder wenigstens ein ... Fragment.

Religionsphilosophie: Die Weisheit und ihre Surrogate. 21. XII. 1913.

Modernismus und Protestantismus. 19. V. 1908.

Modernismus und Protestantismus. 23. VIII. 1908.

Modernismus überraschend. Man glaubte nicht mehr an die Möglichkeit so mächtiger religiöser Interessen ...

Protestantismus und Modernismus. Die Religion vornehmste Erscheinung in der Geschichte der Menschheit ... 22. Mai ? 
Kritische Bemerkungen zu Schell: Die Welt und Gott. 1 Blatt mit Schönbühel, 28. XI. 11 datiert.

Religion der Inder. LXIXa: Die Meinungen über sie gehen immer noch weit auseinander ...

Bemerkungen zu Kemmerichs „Prophezeiungen“. München. 1911.

Philosophie und Theologie. Die Theologie entwickelt eine Glaubenslehre vom Göttlichen, die ...

Zur Religionsphilosophie: Es gibt eine Wissenschaft, welche uns über den letzten und über ... Jänner 1907.

Zur Religionsphilosophie: Wir sehen heute einmal über das anderemal ein Buch erscheinen ... 18. XII. 1907.

Religionsphilosophie: Gesichtspunkte. Jänner, Dezember 1907.

Von der Religion: I. Buch Von der Weisheit. Was sie sei? Erkenntnis des ersten Grundes aller Dinge ... 18. XII. 1907.

Fragment eines Briefentwurfes (an den Abt Haneberg) beim Abschied vom Christentum.

Modernismus: Die modernistische Bewegung, welche die katholische Kirche in Aufregung setzt, wird auch ...

Begriff der Religion: Uneinigkeit der Bestimmungen derselben ... 22. VI. 1912.

Die christliche Glaubenslehre: Die Weisheit Gottes. Teilnahme an derselben durch den Glauben ... 26. IX. 1912.

Die christliche Glaubenslehre: Gott ist ein unmittelbar notwendiges, unendlich vollkommenes Wesen ... 29. IX. 1912.

Religionsphilosophie: Religion. Religion und Philosophie. Glauben ... 10. X. 1904.

Religionsphilosophie: Definition des Begriffes Religion. Schwierigkeit derselben ... Jänner 1907.

Ich habe in letzter Zeit fast nur Theologica geschrieben. Neues Testament, Altes, ...

Über „Hibbert Lectures“ v. le Page Renouf. Florenz. 29. IV. 1904.

Über Modernismus. Fragment: In der Geschichte der Menschheit ist keine Erscheinung interessanter als die ...

Religionsphilosophie. Die Weisheit. Die Einheit der Weisheit ... 24. VI. 1914.

Manuskripte und Diktate.

XLVI. Auerbach: Die Weltherrin und ihr Schatten. Diktat. 2 Exempl. 3 xBg.

Abschriften.

XLVI. Auerbach. Die Weltherrin und ihr Schatten.

Boltzmann: Es gibt nicht eine, sondern viele Welten ... 
Boltzmann. Unentbehrlichkeit der Atomistik. Methoden in der theoretischen Physik. Atomistik und Phänomenologie ... 1896.

Boltzmann: Populäre Schriften. Über die Frage nach der ... 3. V. 1916.

Von der Trägheitstendenz. 20. V. 1916.

Kritisches zu Planck. 8 Vorträge. Florenz. Mai 1910.

Von der Zahl und dem analytischen Charakter der algebraischen Wahrheiten: Es gibt unbestimmte Begriffe. Unter sie kann solches fallen, was reell ...

Abschriften.

XLVII. Zur Universalienlehre: Schon von Aristoteles wurde erkannt und erwiesen, dass wir allgemeine ... 2. VI. 1916.

Zur Lehre von Anschauung und Allgemeinbegriff: Kant unterschied Anschauung und Begriff in der Art ... 11. II. 1916.

Begriff: Die Verwirrung, welche heute die Philosophie am gemeinsamen Fortbau der Wissenschaft ... Mai 1906.

Zur Lehre von den Universalien: Zeitlichen Abstand aber sprechen wir, und so scheint denn die Vorstellung [sic!] ... 12. I. 1915.

Abschriften von Marty und Kraus.

XLVII. Vom Nominalismus gegen Guastalla: es gibt nicht leicht eine Tatsache, die besser gesichert wäre als die ... Palermo. Von Marty. 1900.

Vom Nominalismus gegen Guastalla: es gibt nicht leicht eine Tatsache ... Palermo. Von Kraus. 1900.

Manuskripte und Diktate.

XLVIII. Logikkolleg. Mskpt. 492 Bl. Beginn am 15. X. 1878.

Manuskripte und Diktate.

XLIX. Plan eines Logikkollegs. Mskpt. $10 \mathrm{Bg}$.

Abschriften.

XLIX. Abschrift des Logikkollegs. Einleitung, bis S. 63 in 3 Exemplaren.

Abschriften.

L. Psychognosiekolleg. Abschrift plus Inhaltsverzeichnis von Hillebrand? Beginn am 17. X. 1890.

Manuskript.

LI. Psychognosiekolleg. Mskpt. 288 + 5 S. Beginn am 17. X. 1890. 


\section{Abschriften.}

LI. 2 Kopien des Psychognosiekollegs 1890/91 plus Anmerkungen für die Psychognosie von Hillebrand.

LII. Von den Sophismen und ihrer Anwendung auf politischem Gebiete. Mskpt. $101 \mathrm{~S} .+2 \mathrm{Bl}$.

3. V. 1876. [Leer. Manuskripte bei Prof. Kastil, Innsbruck.]

Abschriften.

LIII. Von den Sophismen und ihrer Anwendung auf politischem Gebiete. $3 \mathrm{Ab}$ schriften.

3. V. 1876.

I al. Des Widerspruchs: wo keiner ist ... 3 Abschr.

Sophismen von Mill. Fallaciae inspectionis oder fallaciae a priori ... $3 \mathrm{Ab}$ schriften.

Manuskript.

LIV. Ethikkolleg. Inhaltsangabe. Einleitung. Mskpt. 16-16 h S. 1875/76.

Ethikkolleg. 1. Abschnitt: Von den Prinzipien ethischer Erkenntnis. S. $17-82$ S. + 40-40v. Mskpt. 1875/76.

Manuskript.

LV. Ethikkolleg. 2. Abschnitt: Vom Guten und Nützlichen. S. 83-144 + Beilagen. Mskpt. 1875/76.

LVI. Ethikkolleg. 3. Abschnitt: Von der Freiheit des Willens. S. 145-153. Mskpt. $1875 / 76$.

Ethikkolleg. 4. Abschnitt: Von der Sittlichkeit im Allgemeinen. S. 154-181. Mskpt. 1875/76.

LVI. Ethikkolleg. 5. Abschnitt: Von den sittlichen Vorschriften im Allgemeinen. S. 181-242. Mskpt. 1875/76.

Ethikkolleg. 6. Abschnitt: Von den sittlichen Dispositionen. S. 243-248. Mskpt. 1875/76.

Ethikkolleg. 7. Abschnitt: Von der ethischen Führung. S. $249-269+4$ Bl. $1875 / 76$.

Manuskript.

LVII. Praktische Philosophie. Skizze eines Kollegs. Mskpt. 13 xBg. Begonnen am 13. X. 1879. 
Abschriften.

LVII. Praktische Philosophie. Skizze eines Kollegs. Mskpt. Begonnen am 13. X. 1879.

Manuskripte und Diktate.

LVIII. Sprache. Die Sprache hat uns als Mittel zu dienen ... Diktat. 5 Str. 11. II. 1914. Sprachwissenschaftliche Einteilung. Mskpt. 1 xBg.

Abschriften.

LVIII. Grammatikalische Abstrakte als sprachliche Fiktionen. Aus dem Briefe Martys vom März 1901.

Sprache. Fragment. Wer sich ausspricht, sagt ... 16. XI. 1905.

Zur Sprache. Zur Lehre von den Temporal-Modis. Die Sprache geht darauf aus, in der Seele ...

Sprachphilosophisches. Relativa sind keine Namen. Was denkt, im weitesten Sinne des Wortes genommen ...

Die Sprache: Die Sprache hat uns als Mittel zu dienen. Abschrift. 11. II. 1914. Die Sprache. Das Sprechen ist ein actus imperatus des Willens.

Zur Sprachphilosophie: Die allgemeine Sprachwissenschaft verdient wahrhaftig den Namen ...

Aussage: Eine Aussage, wenn vollkommen wahrhaftig, ist der Ausdruck eines überzeugten Urteils und ist bestimmt ...

Die Sprechenden, die Denkenden, die Dinge. Zürich. 5. III. 1916.

Sprache: Sprechen kann einer nur über solches ... 9. II. 1914. „Ist“ im Sinne von „es gibt“: Ihm zur Seite steht ... 4. II. 1914.

Von der Sprache: Zeichen ist etwas, dessen Erkenntnis ...

Sprache: 1. Welche Worte zu erklären? Wie die Erklärung ... 2. II. 1914.

Sprache: Durch die Sprache geben wir uns als Denkende ... 10. II. 1914.

Abschriften.

LIX. Abschrift des Ethikkollegs von Prof. Winternitz. I. + II. Abschnitt. Begonnen am 17. Okt. 1881.

LX. Abschrift des Ethikkollegs von Prof. Winternitz. III. + IV. Abschnitt. 1881.

Manuskript.

LXI. Stenographiertes Ethikkolleg von Winternitz, wovon in Mappe LIX und LX Abschrift. 17. Okt. 1881.

Abschriften.

LXII. Ethikkolleg. Abschrift nach dem Kollegienheft von Oelzelt. 


\section{Abschriften.}

LXIII. Ethikkolleg. Stenographiertes Kollegienheft, unabgeschrieben, schwer leserlich.

Nachschriften.

LXIV. Die elementare Logik und die in ihr nötigen Reformen. Stenographiertes Kollegienheft von M. Winternitz nach den Vorlesungen F. Brentanos. $1884-85$.

Abschriften.

LXV. Die elementare Logik und die in ihr nötigen Reformen. Abschrift des Kollegienheftes von Winternitz. 1884-85.

\section{Abschriften:}

LXVI. Logikvorlesungen, nach Kastils Bemerkungen. I. Vor 1875.

Abschriften:

LXVII. Logikvorlesungen, nach Kastils Bemerkungen. II. Vor 1875.

Abschriften:

LXVIII. Alte und neue Logik. Nach Dr. Brentano. 1877.

Manuskript.

LXIX. Descriptive Psychologie oder beschreibende Phänomenologie. Mskpt. 3 xBg. Einleitung 112 S. $1888-89$.

Abschrift.

LXX. Descriptive Psychologie oder beschreibende Phänomenologie. Abschrift. $1888-89$.

Lithographierte Abschrift.

LXXII. Antritts-Vortrag des Dr. Franz Brentano. Lithographierte Abschrift, Wien. 22. IV. 1874.

LXXIII. Thesen 1866, gedruckt. 1866.

Abschriften.

LXXIV. Neuer Versuch einer Synechologie: Eine Größe ist, was ...

Über Abstände von Qualitäten und Helligkeiten: Wie die Intensität lässt die Helligkeit keine kleineren als Teile ... 
Zur Kontinuitätslehre, nichteuklid. Geometrie: Keine Anschauung a priori. Zahl, Zeit und Raum ...

Vom Maß des Kontinuierlichen: Jedes Kontinuum ins Unendliche differenziert. 1, 2 ...

Kontinuum. Sein Verhältnis zu den Grenzen: Eine kontinuierliche Substanz besteht aus Teilen, welche ...

Vom Unendlichen: Die Mathematik, in der Lehre von ihrem ...

Zur Lehre vom Unendlichen: Die Betrachtung des Endlichen ...

Zur Lehre vom Unendlichen. Paradox: Wenn zwei von jetzt ...

Einleitung zu einem Vortrag über das Unendliche: Auf die Frage nach dem Unendlichen ...

Fragment über das Unendliche.

Brentano an Enriquez. Abschrift eines Briefes.

Bolzano, Paradoxien des Unendlichen. Leipzig 1851.

Paradoxien für Kontinua: i, es ist, scheints, eine Realität und zugleich viele ...

Vom Kontinuierlichen. Inhaltsangabe (verf. v. O. Kraus). Wie alle unsere Begriffe ist auch der Begriff des ...

Vom Kontinuierlichen, v. Fr. Br. Inhaltsangabe. Nach Anmerkungen von Kraus.

Vom Kontinuierlichen: Ursprung der Begriffe. Gesichtspunkte unter welchen es zu betrachten ... Mit Anmerkungen von Kraus. 1914.

Manuskript.

LXXV. Synechologie. Mskpt. Heft.

Abschriften.

LXXV. Von der Existenz eines Kontinuums: Man behauptet man habe ... 1906? Kontinuum (Holokterie, Teleiose). Jedes Kontinuum besteht aus Kontinuum [sic!] bis ins Unendliche. Die Frage ist ...

Von der Natur des Punktes: Über die Natur des Kontinuums denken die heutigen Geometer vielfach nicht richtig ...

Von dem Unterschied zwischen primärem und sekundärem Kontinuum: Es wird gut sein, diesen Unterschied ...

Über die Möglichkeit eines Kontinuums: Seit Jahrtausenden streitet man über die Möglichkeit eines Kontinuums ...

Über die Möglichkeit eines Kontinuums: A. II. Was gehört dazu, um zu erkennen, dass etwas möglich ist? - Vielfach sagte man ...

Brentano - Notizen 1913 aus Schönbühel. 1913.

Begriff der Teleiose: Bei jeder Größe, welche Teile hat ... 
Brentano - Notizen, Anmerkungen von Kraus.

Eine Zahl ist eine Bestimmung des Wieviel. Eine Größe ist ...

Vom Kontinuierlichen: Ursprung des Begriffs - Gesichtspunkte ...

Raumvorstellung: Woher stammt unsere Raumvorstellung? Wie kommt es, dass die Frage überhaupt in der Wissenschaft ...

Aristoteles und Leibniz erklären beide, dass ein Ding unmöglich ... 8. V. 1916.

Zur Kontinuitätsfrage: Der Begriff des Kontinuums kann nicht in der Art wie Poincaré wollte ... Florenz. 17. III. 1913.

Abschriften.

LXXVI. Lobatschefskij: Nach L. gibt es in der Ebene Pseudokreise ...

Raumvorstellung: Empirischer Ursprung. Die Lehre von angeborenen ... Vom Raum: Hinsichtlich des Raumes haben unfraglich diejenigen ... Über den Inhalt der Raumvorstellung. Entwurf für Dr. Eisenmeier, Anfang fehlt. 9. II. 1906.

Vom Ursprung der Raumvorstellung. Psychogenetische Fragen abhängig ... 1906?

Zur Lehre vom Raum. 7. II. 1915.

Abschriften von Marty.

LXXVI. Woher unsere Raumvorstellung? Wie kommt es, dass diese ... Zwei Abhandlungen über den Raum. Von Brentano.

1. Die Frage scheint genetisch; aber mit Psychognost. zu beginnen ...

2. Die Frage scheint psychogenetisch, aber mit Psychognostik ...

Vom Raum: Hinsichtlich des Raumes haben unfraglich ...

Abschrift.

LXXVII. Zur Lehre von Raum und Zeit: Das Ganze der Abhandlung, deren Teil in den Kantstudien XXV. publiziert wurde ... 23. II. 1917.

Manuskript.

LXXVIII. Von der Zeit. Mskpt. 2 xBg.

Abschriften.

LXXVIII. Von der Zeit: Wir haben Anschauungen von Wechsel ...

Die Zeit. Aus Martys Kolleg, Brentanos Lehre. Bereits publiziert in dem Archiv für gesamte Philosophie, Bd. 74. 1 lithographierte Kopie und eine Maschinenabschrift. 1895? 
Marty- und Kraus-Abschriften.

LXXVIII. Aus einem alten Psychologiekolleg über Zeitvorstellung. Abschrift von Marty: Soviel von dem nicht realen Charakter der zeitlichen Bestimmtheiten ...

Zur Geschichte des Zeitproblems bei Brentano und Marty. Bemerkungen Brentanos zur Zeitlehre aus verschiedenen Jahren. Marty-Abschrift.

Der Zeitbegriff stammt aus der inneren Wahrnehmung und zwar aus der Wahrnehmung von Urteilen ... Marty-Abschrift, scheint von Brentano? (Marty) 1898?

Über die Zeit. Stenographierte Abschrift eines Briefes von Brentano an? 20. XII. 1899.

Abschriften.

LXXIX. Marty, Zeit. Nach Marty wäre das Zeitmoment, das uns ... (vide Brief an Kraus Herbst 1914).

Martys Lehre von der Zeit und meine Lehre von der Zeit. 14. X. 1914.

Meine Lehre von der Zeit. 14. X. 1914.

Zur Lehre von der Zeit. Was ist unter Zeit zu verstehen? Zunächst scheint es mir angezeigt, sich Beispiele von ... 1914?

Von der Zeit. 10. XI. 1914.

Die Zeit. 15. XI. 1914.

Einwände gegen die Temporalmodi (gegen Marty): Wenn jedes Vorstellen als gegenwärtig oder als ... (mit Anmerkung von Kraus).

Von der Zeit. 2. XI. 1914.

Zur Zeit. 15. XI. 1914.

Fortsetzung zu Absatz 3 (weglassen). 28. XII. 1914.

Von der Zeit. 2. V. 1908.

Diktat.

LXXX. Gegen die Zeitlehre Martys. Diktat. 11 Str. 24. I. 1915.

Abschriften.

LXXX. Lehre von der Zeit: Wir denken die Gegenwart als Grenze ...

Von der Zeit. 4. I. 1915.

Ob die Temporalmodi zu den modis obliquis zu rechnen. 18. I. 1915.

Gegen Martys Zeitlehre. 24. I. 1915.

Zur Lehre von der Zeit. 4. II. 1915.

Zur Zeit. Forderungen, welchen eine Zeittheorie genügen muss. 6. II. 1915.

Zur Zeitlehre. 7. II. 1915.

Zur Lehre von der Zeit. 9. II. 1915. 
Über unmittelbare Zeitfolge, zeitliche Berührung und unmittelbaren zeitlichen Zusammenhang. 9. II. 1915.

Zur Zeitlehre. 13. II. 1915.

Raum und Zeit. 14. II. 1915.

Die Zeit. 28. II. 1915.

Die Zeit. 1. III. 1915.

Von Differenzen, welche unterindividuell sind. 1. III. 1915.

Was versteht man gemeiniglich unter Zeit? 3. III. 1915.

Ausgangspunkte für die Untersuchung über die Zeit. 4. III. 1915.

Zur Lehre von der Zeit. 6. III. 1915.

Die Schwierigkeiten der Zeitfragen. 8. III. 1915.

Von der Zeit. 22. III. 1915.

Früher und später. 29. IV. 1915.

Aporien der Zeitlehre. 30. IV. 1915.

Manuskripte.

LXXXI. Von der Zeit: Die Zeit ist einer der uns geläufigsten Ausdrücke ... Mskpt. 10 xBg. Undatiert.

Zur Lehre von der Zeit. (Entweder Abschrift oder Diktat.) I. u. II. Teil. Undatiert.

Abschriften.

LXXXI. Zur Lehre von der Zeit: Frühere Untersuchungen von mir haben dargetan ... Undatiert.

Von der Zeit: Zeit ist einer der uns geläufigsten Ausdrücke. Abschrift des Manuskriptes. Undatiert.

Zur Frage von der Zeit: 1. Wäre die Zeitbestimmung eine Differenzierung des Objektes, wie die ... Undatiert.

Von der phänomenalen Zeit. Man hat die Zeit oft ... Undatiert.

Raum und Zeit: Woher stammt der Zeitbegriff ... Undatiert.

Zur Lehre von der Zeit. Bruchstück (unvollendet). 2 Exemplare. 28. VI. 1916.

Kraus - Notizen zur Zeit.

LXXXII. Über voraussetzungslose Forschung. Münchener Neueste Nachrichten. Publiziert in Zukunft der Philosophie.

Manuskript.

LXXXIII. Vom Monismus. Mskpt. 79 Bl. + 4 S. Beilage.

Positivismus. Mskpt. 90 Bl. + 11 Bl. 1893/94.

Vorarbeiten zu einer Kritik des Monismus. Mskpt. 
Abschrift.

LXXXIII. Vom Monismus, in drei Abschriften.

Manuskript.

LXXXIV. Unsterblichkeitskolleg I.

Abschrift.

LXXXIV. Unsterblichkeitskolleg. Abschrift. I. Teil.

Manuskript.

LXXXV. Unsterblichkeitskolleg. Mskpt. 157 Bl. 1875/76.

Abschrift.

LXXXV. Unsterblichkeitskolleg. Abschrift. II. Teil.

Manuskript.

LXXXVI. Descriptive Psychologie. Mskpt. 300 S. 1887/88.

Manuskript.

LXXXVII. Descriptive Psychologie. Mskpt. S. 300 - 647 + Anmerkungen. 1887/88.

Manuskripte und Diktate.

LXXXVIII. Vorwort: Von den hier vereinigten Vorträgen ... Diktat. Undatiert. Metaphysik. Diktat. 33 Str. 16. XI. 1915.

Von der Bestimmung qualitativer Abstände. Diktat. 3 Str. 6. III. 1916. Über Eisenmeiers „Helligkeit“. Mskpt. 22 Str. 3 xBg. Reinschrift und Abschrift bei den Marty-Briefen. Undatiert.

Von der Ausfüllung des blinden Fleckes. Fragment. Mskpt. 2 xBg. Undatiert.

Rückblick auf meine Artikel über ein optisches Paradoxon. Mskpt. 22 Str.

Nach 1896.

Nachtrag zur Intensitätslehre. Diktat. 4 Str. 18. III. 1914.

Vom Sinnesraum. Mskpt. 16 Bg. Undatiert.

Von den Universalien. Diktat. 20 Str. 12. I. 1915.

Kants seltsame Intensitätslehre. Diktat. 3 Str. 20. IV. 1916.

Manuskript.

LXXXIX. Gründe gegen den Empirismus. Mskpt. 181 S. plus Anmerkungen. 
Abschrift.

XC. Gründe gegen den Empirismus. Abschrift.

Manuskript.

XCI. Über Schellings Philosophie in ihren verschiedenen Phasen, Darstellung und Kritik. Mskpt. oder Diktat. (?) Bei der Habilitation. 7 xBg. 1866.

Über Schellings Philosophie. Vortrag gehalten in der Wiener philos. Gesellschaft. Mskpt. 26 Bl. 17. XII. 1889.

Diktat \& Abschrift v. Prof. Kraus.

XCII. Rätsellösungen.

Manuskript.

XCIII. Ontologie. Zwei Faszikel. Mskpt.

Manuskript.

XCIV. Moderne Irrtümer über die Erkenntnis der Gesetze des Schließens. Vortrag gehalten in der Wiener phil. Gesellschaft. 34 Bg. 1890/91.

Manuskript.

XCV. Theologie. 10 Bg. +2 (2xBg).

Manuskript.

XCVI. Metaphysik. Grosses mit Bleistift geschriebenes Kolleg. Nicht photographiert, nicht abgeschrieben, wichtige Teile von Kastil mit der Hand abgeschrieben.

Manuskript.

XCVII. Ausgewählte Fragen aus Psychologie und Ästhetik. Inhaltsangabe. Mskpt. $8(2 \mathrm{xBg})+2$ Bg. 1885/86.

Ausgewählte Fragen aus Psychologie und Ästhetik. Mskpt. S. 1-200.1885/ 86.

Ausgewählte Fragen aus Psychologie und Ästhetik. Mskpt. S. 201-Schluss. $1885 / 86$.

Abschrift.

XCVIII. Ausgewählte Fragen aus Psychologie und Ästhetik. Abschrift. Inhaltsangabe. 66 Bl. Koll. 1885/86. 
Abschrift.

XCIX. Ausgewählte Fragen aus Psychologie und Ästhetik. Abschrift. S. 1-116. Koll. $1885 / 86$.

Abschrift.

C. Ausgewählte Fragen aus Psychologie und Ästhetik. Abschrift. S. 117-Schluss. Koll. $1885 / 86$.

Manuskripte.

CI. Wesenhaftes und Unwesenhaftes. Aufzeichnungen und Aphorismen. Mskpt. $10 \mathrm{xBg} .+5 \mathrm{Bg}$.

5 Hefte über Wesenhaftes und Unwesenhaftes. Heft 1, 2, 3, 5,6, in dem Heft. No. 1 von der letzten Seite 35 Seiten nach vorwärts eine Abhandlung über Synechologie. Mskpt.

CII. Eine Mappe Russell-Paradoxon mit Anmerkungen von Prof. Kastil versehen.

Abschriften.

CIII. Von den logischen Teilen. Ob von ihnen die Metaphysik? Abschrift. 20 Seiten.

Brentano: Aristoteles' Erkenntnislehre. Abschrift von S. 7-14. Ihr Objekt als etwas unmittelbar zeitlich ...

Fr. Brentano: Aristoteles: Chronologie seiner Werke. Zum Biographischen. Abschrift,

S. $1-18$.

Axiome und Kontradiktion. Zur Erkenntnistheorie. Abschrift, Seite 1-5.

Aristoteles Bedeutung und Verkennung. (Einleitung zur Darstellung seiner Lehre.) Abschrift $2 \mathrm{~S}$.

Selbstanzeige von Aristoteles und seine Weltanschauung. Abschrift, koll. 2 Seiten.

Aristoteles Lehre von der mannigfachen Bedeutung des Seienden. Abschrift 5 Seiten.

Brentano, Aristoteles' Terminologie. Abschrift 1-17. 2 Exemplare.

Ontologie. Ding und Unding. Abschrift, 1 Seite.

An Th. Gomperz. Über Theophrast, Aristoteles, Lehre vom Wirken der Gottheit. Abschrift koll. 3 Seiten. 7. September 1904.

Aristoteles Metaphysik als Lehre vom Realen im allgemeinen. Abschrift 3 Seiten. 23. April 1908.

Die verschiedenen Definitionen der Metaphysik bei Aristoteles. Abschrift 5 Seiten.

24. April 1908. 
Gottes Erkenntnis von der Welt nach der aristotel. Metaphysik. Abschrift 3 Seiten.

24. April 1908.

Aristoteles Ontologist? Abschr. 2 Seiten. 6. Mai 1908.

Zur Kosmologie des Aristoteles. Abschr. 3 Seiten. 6. März 1909.

An Tvorkovsky, Abstraktion und Induktion und intellectus agens. Abschrift 4 Seiten. Oktober 1909.

An Benn? Intellectus agens. Materia prima. Abschrift. $4 \mathrm{~S}$.

An Benn. Über Weltzweck und göttliche Providenz bei Aristoteles. (Zu Metaphysik $\Lambda 10$ und Nic. Eth.) Abschrift. 3 S. 2 Exempl. 17. Mai 1910.

An Rolfes, Über Aristoteles' Semimaterialismus, die Lehre von Gottes Unveränderlichkeit und seinem Determinismus. Abschrift. 6 Seiten. 1. Juni 1910.

Aristoteles’ Lehre von Gott und Welt. Abschrift. 9 Seiten. 27. Jänner 1909. Zur Frage über Substanz und Akzidens. 4 Exempl. Abschrift. 3 Seiten.

Transcencente Verhältnisbegriffe. Abschrift. 2 Seiten. Handschrift Br., sehr schlecht.

Abschriften.

CIV. Metaphysik, Transzendentalphilosophie. 4 Abschrifte. 76 Seiten.

Abschriften.

CV. Ontologie. Abschrift. Ohne Anfang Seite 113-219.

Abschriften.

CVI. Aristoteles Metaphysik. Gedankengang des Buches. Abschrift 26 Seiten.

Zur Metaphysik $\Lambda$ Pag. 1075 b 20. Abschrift. 7 Seiten.

Übersetzung $\Lambda 9$ Kapitel, und Fragen dazu. Aporien. 1 Fassung, Abschrift 37 Seiten.

Aporien, 2. Fassung. Abschrift 46 Seiten.

Aporien, 3. Fassung. Abschrift 60 Seiten.

Manuskript.

CVII. Vom Dasein Gottes. I. Mappe. Mskpt. 1891/92.

Manuskript.

CVIII. Vom Dasein Gottes. II. Mappe. Mskpt. 1891/92.

Manuskript.

CIX. Vom Dasein Gottes. III. Mappe. Mskpt. 1891/92. 
[Handschriftliche Ergänzung von Kastil:]

Mskp. Geschichte der Philosophie (altes Kolleg). Streifen, Bleistift. 2 Pakete. 19/XII 33 durch Dr. Hollaender nach Prag.

\section{Verzeichnis der in Schönbühel befindlichen Briefe an und von Franz Brentano $^{7}$}

A

No 1 ADLER Ludwig (Jude durch F. Brentano zum Christentum geführt und Dominikaner geworden) etwa 20 Briefe aus der Zeit 1855 bis 1905. Die Briefe sind bald Franz Adler bald Ludwig gezeichnet und sowohl an Franz Brentano als an seine Mutter Emilie gerichtet.

No 2 AMENDOLA (Giovanni) in italienischer Sprache ca 3 Briefe 1909-1912.

No 3 ARLETH 9 Briefe (1 Brief an Marty dabei) 1898-1908.

No 4 ARNOLD 9 Briefe und Karten handelt meistens von Rätseln 1910 - 1914.

No 5 ASTER (Prof.) 12 Briefe aus 1909-1912.

\section{B}

No 6 BERGMANN (Hugo ehemaliger Schüler Prag Jerusalem) 1906-1914 Teilweise wissenschaftlichen Inhalts. ca 20 Stück.

No 7 BOLZMANN (Ludwig Prof. der Physik, später Naturphilosophie) 10 Briefe von ihm und 3 von seiner Witwe aus den Jahren 1903-1906. Teilweise wissenschaftlich.

No 8 BREITENEDER OSM Innsbruck 1 Brief 1909.

No 9 BREUER Josef (Arzt der Familie Lieben und Brentano. Begründer der Psychoanalyse. 13 Stück (Briefwechsel über Darwinismus hat Kraus) Recht zur Publikation der Breuerbriefe von Breuer selbst zugestanden. 1895-1913.

C

No 10 CALDERONI. Ein Brief von Brentano an C. Über Relativismus 1906.

No 11 CLÖTER (Verfasserin eines Werkes von Wiener Schilderungen darunter des Hauses Brentano) 3 Briefe 1911.

E

No 12 EHRENFELS (Christian Frh. von, Professor in Prag) 39 Briefe ein Brief von seiner Mutter Clothilde und 2 von seiner Frau Emma. Von 1893 bis 1908.

7 Die kursiven Nummern bezeichnen Konvolute von Briefen, die sich bei Kraus im Prager Brentano-Archiv befanden. 
Verschiedenen Inhalts. Zwei Briefabschriften an E. sind bei Kraus zum Abschreiben.

No 13 EBBINGHAUS H. (Professor) Ein Brief aus 1892.

No 14 EISENMEIER Josef Professor in Prag 62 Briefe 2 Exzerpte eine Karte seiner Frau Tusnelda Zeitungsausschnitte Die Briefe aus dem Jahr 1902-1912 zum größten Teil wissenschaftlichen Inhalts.

No 15 EBNER ESCHENBACH, Marie (Dichterin) 4 Briefe aus 1903.

No 16 EDEL Ernst Margarethe 6 Briefe 1875-1876.

$\mathbf{F}$

No 17 Schwester Maria FELICITAS (Nichte des Mahlers Führich) 17 Briefe aus den J. 1909-1913. Ein Brief von ihr an P. Sinbourg S.I. und ein Brief von Schwester Serafica (Schwester von Franz Brentano) an Schw. Felicitas.

No 18 FÜHRICH M. S.I. Bruder der Schw. Felicitas. 5 Briefe 1910 - 1911.

\section{G}

No 19 GAGERN (Freiherr von) 5 Briefe (Abschriften ??) an Brentano aus den Jahren 1879-1887 und 28 Briefe F. Brentanos an Gagern aus den J. 18731884. Ein Brief von Sophie Funck Brentano an Gagern und ein Brief der Baronin Gagern an ??

No 20 GOMPERZ Theodor (Professor in Wien) und sein Sohn Harry 5 Briefe an Th. Gomperz - Brentano 1908, ein Brief an Lieben (Richard?) 1893.

No 21 GÖRRES Sophie zwei Briefe aus 1912, 1913.

No 22 GRATL Arimatias Prior in Schönbühel und andere Prioren 62 Briefe 19051913.

H

No 23 HAUSER Famile (viele ungeordnete Briefe).

No 24 HAHNEBERG (Abt. Freund Brentanos in dessen Kloster er sich später zurückzog, um alles für und wider die Göttlichkeit der Kirche zu erwägen) 2 Briefe aus 1874.

No 25 HASENÖHRL F. (Professor in Wien Physiker) 4 Briefe 1903 wissenschaftlichen Inhalts betreffend die Entropie 1902-1903. Ein Auszug aus Bolzmann Gastheorie.

No 26 HERTLING Georg von (Kanzler des Deutschen Reiches, ein Vetter Brentanos). Drei Briefe von Hertling an Brentano 1861, 1893, 1911 und drei Brouillons v. Briefen F. Brentanos an Hertling undatiert. Dabei noch zwei Briefe von Hertling Peter Josef von. Rentier aus 1903. Im Ganzen 8.

No 27 HERZ Julius 11 Briefe aus 1896-1907 und ein Brief von Henriette Herz 1894. 
No 28 HERZEN Alexander und N. vom ersten ein Brief (Französisch) 1896 vom zweiten 2 Briefe (französisch) 1908.

No 29 HILLEBRAND Franz (Professor in Innsbruck) etwa 40 Briefe teilweise wissenschaftlichen Inhalts (Sinnespsychologie!) 1907-1914. Eine Abhandlung Exzerpt(?) über Lobatschevskijs „imaginäre“ oder Pangeometrie und eine Besprechung des Artikels „Das Verhältnis von Akkomodation und Konvergenz zur Tiefenlokalisation Z. f Ps Bd VII.

No 30 HERING E. (Professor in Leipzig) 3 Briefe aus 1895, 19041907 und ein Brief von F. Brentano an ihn aus 1907 bei der Überreichung der „Sinnespsychologie“.

No 31 HENNEMANN K. (katholischer Schriftsteller) etwa 27 Briefe apologetischen Inhalts aus 1907-1914.

No 32 HUSSERL Edmund (Professor in Hall, Göttingen, Freiburg) 7 Briefe wenig wissenschaftlich. Aus 1886-1913.

No 33 HIRSCH Ignaz (ehemaliger Sekretär Brentanos) 16 Briefe teilweise wissenschaftlichen Inhalts aus 1904-1913.

\section{J}

No 34 JAENSCH (Professor in Marburg) ein Brief aus 1914.

\section{K}

No 35 KASTIL Alfred (Professor in Innsbruck) etwa über 60 Briefe 1896-1914 zum kleinsten Teil wissenschaftlichen Inhalts ein Excerpt aus Meyer.

No 36 KÖHLER Wolfgang (Professor in Berlin) Ein Brief von F. Brentano an ihn und ein Brief von F. Brentano über ihn an Stumpf betreffend seine Theorie der Vokale.

No 37 KIRSCHKAMP Ein Brief aus 1908.

No 38 KLATSCHER Camill 8 Briefe aus 1906-1914.

No 39 KURZ Isolde 7 Briefe um 1897.

No 40 KRAUS Oskar (Professor in Prag) hat den Faszikel in Prag.

No 41 M. K. (??) 8 Briefe und ein Fragment aus ca. 1899.

\section{L}

No 42 LEDERER Max 7 Briefe und ein Brief von Selina Hummel geb. Lederer aus $1890-1913$.

No 43 LEHMANN Pater Ein Brief 1897 theologischen Inhalts.

No 44 LIPPS Theodor (Professor in Breslau) 3 Briefe an Brentano und ein Brief von Brentano an Lipps aus 1892 (betreffend optische Täuschungen).

No 45 LUTOSLAWSKI W. 16 Briefe philosophischen Inhalts. 
M

No 46 MACH Ernst (Professor in Wien) 6 Briefe 1895-1910.

No 47 MARTY Anton Professor in Prag ca 34 Briefe sind bei Professor Kraus in Prag mit den übrigen Korrespondenzen Brentano Marty und umgekehrt.

No 48 MEINONG Alexius (Professor in Graz) Ein Brief 1882 betreffend seine akademischen Erlebnisse.

No 49 MEISSNER (?) 4 Briefe aus 1897.

No 50 MILL John Stuart 2 Briefe von Brentano an ihn aus 1872-1873 die Briefe von Mill sind in Innsbruck.

No 51 MIKLOSICH (Professor in Wien) Ein Brief betreffend serbische Volkslieder undatiert.

No 52 MÜNZ Bernhard (Journalist) Ein Brief 1886.

$\mathbf{0}$

No 53 OESTERREICH Traugott Konstantin (Professor) Ein Brief aus 1913 und ein Brief von Brentano an ihn.

No 54 ORESTANO Francesco über 60 Briefe aus 1899-1908.

$\mathbf{P}$

No 55 PEROUTKA Pfarrer Bekehrungsversuche 57 Briefe.

No 56 PETRONIEWICZ Branislav (Professor in Belgrad) 6 Briefe teilweise wissenschaftlichen, teilweise biographischen Charakters.

No 57 PIDOLL Freiherr Direktor des Theresianums 25 Briefe aus 1882-1914.

No 58 PLENER Ignaz Freiherr von Geheimrat 19 Briefe aus 1892-1914.

No 59 POJERO AMATO (Geheimrat) Viele Briefe in italienischer Sprache.

No 60 PUGLISI Mario I Viele Briefe in italienischer Sprache meistens persönlichen Inhalts.

No 61 PUGLISI Mario II ebenfalls.

No 62 Psychologischer Kongreß in Rom Vter. Drei Briefe vom Sekretariat unterzeichnet: Sante de Sancti und ein Brief von der Präsidenz unterzeichnet $G$ Sergi.

R

No 63 REVESZ Magda (Professor) 9 Briefe 1913, 1914.

No 64 ROLFES Pater Aristotelesübersetzer. 9 Briefe von ihm an Brentano aus 1908 - 1914. Zwei Briefe Brentanos an ihn und ein Fragment eines solchen (?) das Ganze betreffend aristotelische Fragen.

No 65 RUPP Ein Brief aus 1909. 


\section{S}

No 66 SALVADORI 2 Briefe in italienischer Sprache aus 1907.

No 67 SECKENBERGER Otto Dr. 9 Briefe aus 1909-1910.

No 68 STALLO 3 Briefe aus denen ein Frau Prof. Brentano 1897, 1905. [sic!]

No 69 STEINLE Dr. Alphons m. von 7 Briefe aus 1909, 1910.

No 70 STERNECK R. von 2 Briefe 1907.

No 71 SCHELL Dr. Hermann 15 Briefe und 1 Fragment + (Zeitungsausschnitte)

No 72 SCHLEFER Adolf stud. jur. 2 Briefe und eine lange Abhandlung gegen den Theismus.

No 73 SCHLOER Bischof. Ein Brief an Brentano und einer von Brentano an ihn 1906. Streit um die Göttlichkeit der Kirche.

No 74 SCHMIDKUNZ Hans 7 Briefe sinnespsychologischen und apologetischen Inhalts 1887-1910.

No 75 SCHNEIDER G Ein Brief aristotelischen Inhalts 1914.

No 76 SCHNABEL Dr. 5 Briefe und ein Fragment 1903-1906.

No 77 SUMA 19 Briefe in italienischer Sprache 1912-1913.

No 78 STUMPF Carl Professor in Berlin. Bei Prof. Brentano.

No 79 STUMPF Carl beide Faszikeln bei Professor Kraus in Prag zu ordnen.

T

No 80 TVORKOVSKIJ 24 Briefe aus 1909-1913. Hauptsächlich aristotelischen Inhalts.

$\mathbf{U}$

No 81 URBACH Dr. Benno 29 Briefe von 1897-1905.

No 82 UTITZ Emil (Professor) 60 Briefe teilweise wissenschaftlichen Inhalts und zwei Fragmente aus 1905-1910.

V

No 83 VAILATI 25 Briefe in italienischer Sprache teilweise wissenschaftlichen Charakters (Mathematik und Megethologie).

No 84 Alphabetisch geordnete Briefe und Anfragen wegen Rätsel.

No 85 Alphabetisch geordnete Briefe betreffend den Rücktritt Brentanos aus Wien.

No 86 Briefe und Dokumente, die sich auf den Streit um den $§ 63$ und Krasnopolski beziehen.

No 87 Zum 70. Geburtstag (unvollkommen).

No 88 Briefe, Verträge, Rechnungen von Verlegern und Zeitungen.

No 89 BENN A. W. 5 Briefe in englischer Sprache [?] 2 Briefe 1909-1911. 
No 90 BIEGELEBEN Erste und zweite Ausgabe seiner Sonette 1866 (unica) und ein Brief von Brentano, der sich darauf bezieht + Infallibilität [?]

No 91 DENIFLE Heinrich 5 Briefe aus 1868-1869.

No 92 DERR Dr. V. 4 Briefe und Gedichte 1889-1901.

No 93 GEROLD Rosa von 5 Briefe 1875-1894. Einer mit der Abbildung des Hauses Lindenhof, über das Brentano ein Gedicht geschrieben hat.

No 94 MERKEL 1 Brief an ? 1860.

No 95 ZOUBOV Graf Alexis und Maria 17 Briefe 1902-1906.

No 96 Briefe aus der Zeit der Trennung von der Kirche. Von Hertling an Brentano, Brentano und Frau Emilie Brentano an den Abt (später Bischof) Haneberg und umgekehrt. Briefe an Heinrich Denifle und ähnliches (auch Gagern).

No 97 TRENDELENBURG A. (Professor) ein Brief aus 1867.

No 98 Briefe an Brentano alphabetisch geordnet nach den Absendern.

No 99 Briefe an Brentano alphabetisch geordnet nach den Absendern.

No 100 Briefe an Brentano alphabetisch geordnet nach den Absendern.

\section{G. Katkov: Brentano Manuscripts [Inventar der fünf während des Zweiten Weltkrieges an der Bodleian Library aufbewahrten Kisten]}

Case 1.

Aristotelica I-XI

Psychologische Scripten. I. 1-20: II. 21-35: III. 36-50: IV. 51-61: V. 62-75:

1 file Logic.

1 file Versuch über die Erkenntnis.

Case 2.

Sinnespsychologie 1-10: 11-30: 31-40: 40 -43:

Seelenfrage 1-18

Naturwissenschaft

God

Inventory $130-142.9$ files.

Case 3.

Inventory $1-129.16$ files.

Case 4.

Letters. Bretano-Marty, Marty-Brentano. File 1. 1869-1862[1882]: File 2. 18831893: File 3. 1894-1902: File 4. 1903-1908: File 5. 1909-1914: 
1 file Brentano-Kraus. 1893-1917.

1 file copies of letters, Brentano-Schell, Hennemann and Fechner.

1 file letters. Brentano-Stumpf, with index with Stumpf's notes.

1 file letters, Brentano-Schell, Brentano-Husserl and Husserl-Brentano, Brentano-

Breuer, Brentano-Wertheimstein, Brentano-Mill.

1 file varios letters and letters to Ehrenfels and letters from Ehrenfels.

1 file letters, Fechner-Brentano, Brentano-Hennemann, Brentano-Rolfes, Brentano-Bergmann, Brentano-Boltzmann, Koehler and Hillebrand, Fechner-Brentano, photostats of Brentano-Fechner. Unidentified fragments.

1 file letters, Kraus-Brentano.

1 file Metaphysik and Ontologie.

1 file unidentified letters. Fragments.

Case 5.

Time, Space and Continuum, Megetology, letters from and to Enriquez.

1 file Metaphysic 2.

1 cardboard container correspondence with Vailati.

1 file Philosophy of Religion.

1 envelope Philosophy of Religion.

1 parcel with personal papers, poems, etc.

1 box with diaries, devotional poems, etc.

1 file with mislaid papers to be filed in the appropriate files including the correspondence with Spencer.

1 file with inventory and other catalogues.

Auguste Comte Article.

1 file with Kraus notes from Florenz and Schönbühl. 